\title{
Granular Mixing in Nauta Blenders
}

\author{
Shahab Golshan, Reza Zarghami*, Hamid Reza Norouzi and Navid Mostoufi \\ Process Design and Simulation Research Centre, School of Chemical Engineering, \\ College of Engineering, University of Tehran, P.O. Box 11155/4563, Tehran, Iran
}

\begin{abstract}
Flow pattern of particles and their mixing performance in a Nauta blender were studied using the discrete element method. The model was validated by experimental data obtained in a convective conical screw blender and good agreement was obtained. Flow pattern of particles was studied through velocity profiles, granular temperature and streamlines of particles. Effects of sweeping rotation speed, primary rotation speed and impeller diameter on the mixing quality and mixing rate were studied. A vertical circulation pattern in the blender was observed due to the primary rotation of the impeller that produced a convective and layered flow. In this pattern, particles are lifted to the bed surface and then descend at the opposite side of the screw. On the other hand, the sweeping rotation of the impeller pushes the particles along the direction of sweeping which leads to a tangential flow of particles. Combination of primary and sweeping rotations of the impeller results in a three dimensional particle mixing. A semi-stagnant zone is also formed temporarily near the cone axis. It was found that increasing the primary rotation speed (from 5 to $10 \mathrm{rad} / \mathrm{s}$ ) and impeller diameter (from 9.72 to $10.8 \mathrm{~cm}$ ) improve the mixing rate (from 0.02096 to $0.05321 / \mathrm{s}$ and from 0.02462 to $0.034651 / \mathrm{s}$, respectively), while increasing the sweeping rotation speed (from 0.15 to $0.45 \mathrm{rad} / \mathrm{s}$ ) decreases the Lacey index and the mixing rate (from 0.04429 to 0.0313 $1 / \mathrm{s})$. To reach a deeper understanding about the effect of sweeping rotation on the mixing

* Corresponding author, Tel.: (+98-21)6696-7797, Fax: (+98-21)6646-1024, E-mail: rzarghami@ut.ac.ir
\end{abstract}


behavior, eight different sweeping velocities were studied and the maximum mixing rate was observed at $0.05 \mathrm{rad} / \mathrm{s}$.

Keywords: Nauta blender, DEM, flow pattern, mixing, granular flow, granular temperature, Lacey index

\section{Introduction}

Powder mixing is one of the most important operations in preparing the intermediate and finished products in chemical, pharmaceutical, metallurgical, food and ceramic industries [1, 2]. Despite the importance of powder mixing in the everyday life and its long history, its mechanisms still are not well understood in various granular regimes and theoretical models that can describe it are scarce. Coexistence of multiple granular phases and history-dependent rheological behavior are the main difficulties in understanding and developing theories about the granular flow [1]. For example, in a tumbler drum, multiple rheological phases coexist in the granular flow and small variations in the operating conditions of the drum (i.e., rotation speed or fill ratio) lead to changing the rheological behavior of the system. Therefore, extensive fundamental and applied studies are still required in the field of granular mixing $[1]$.

Insights into the granular flow have been gained by extensive experiments [3-5] and modelings [6-9]. Experimental measurements are usually done by frequent sampling of the mixture [3], visual assessments, like capturing images from the surface of the bed and postprocessing then [4] or more advanced methods like positron emission particle tracking (PEPT) or radioactive particle tracking (RPT) [5]. These techniques can provide information 
about mixing kinetics, but they do not provide a deep knowledge of the mixing mechanisms. Instead, detailed models can be helpful in this regard $[6,7]$. Therefore, both experimental and modeling studies are required to gain knowledge about powder mixing. In the past decades, the discrete element method (DEM) has been developing and was proven to be a reliable and powerful tool for simulating granular flows $[6,7]$. One of the limitations of this method is its high computational demand which restricts the investigations to not very large systems. The DEM has been utilized to simulate blenders for obtaining flow patterns of particles [6-8], optimizing their operation $[9,10]$, studying the effect of process parameters on their operation $[7,8,11,12]$ and investigating the effect of particle size distribution on the flow pattern $[13,14]$. This method is widely used for simulating various types of blenders, including rotating drum $[7,13,15]$, vertical bladed [16, 17], paddle [18, 19], Plowshare [9], fluidized bed [20, 21] and high shear [22-25] blenders.

The knowledge of mixing of solid is not complete yet, even in the simple solid flows such as drums or tumblers. This becomes more severe in blenders with rotating shafts or moving parts [14], such as the Nauta blender, since they have a diverse range of body shapes, blade designs and rotor configurations. The Nauta blender consists of a conical body and a screw that rotates around its own axis as well as around the axis of the conical body, simultaneously $[26,27]$. The rotating pattern of screw in the Nauta blender leads to formation of strong circulation flows in the blender [27] with less segregation problems, good axial mixing and emptying conditions $[28,29]$. However, evacuation problems may be encountered in the case of cohesive particles if clearance of the impeller is short. Experiments have been conducted to measure the mixing kinetics in this type of blender [30, 31]. Cook et al. [30] studied the mixing rate of a multicomponent tablet mixture (including phenobarbitone, butobarbitone, 
quinalbarbitone and lactose with diameters of 0.063 to $0.5 \mathrm{~mm}$ ) in a Nauta blender for 64 minutes. They only studied the multicomponent mixing kinetics and the flow pattern was not studied. Berntsson et al. [31] utilized a fiber-optic probe and near infrared spectroscopy to measure particle concentration and provided a new method for in-situ measurement of the chemical content of powder mixtures. A production scale Nauta blender $\left(3 \mathrm{~m}^{3}\right)$ and 0.2 and $0.3 \mathrm{~mm}$ particles were used for this purpose. Van der Bergh and Scarlett [32] conducted a set of experiments in a Nauta blender. The particles used in their work were $0.65 \mathrm{~mm}$ silica sand and the volume of the blender was 120 liter. Mixing responses of the mixer was studied using a radiotracer and a computer program was proposed for estimation of mixing time and design improvement of convective blenders.

The limited experimental works and no simulations on Nauta blenders have left many questions unanswered on the mixing kinetics and flow pattern of particles in this type of blenders. To the best of authors' knowledge, this work is the first DEM simulation study for investigating the granular mixing in the Nauta blender. In the present study, the DEM was used to investigate the flow pattern and velocity profiles of particles. In addition, effect of operating conditions, including speed of rotation of the screw around the blender and around its axis and diameter of the impeller, on the mixing kinetics was investigated. The DEM was also validated with experimental data in terms of velocity distribution and mixing kinetics in a conical blender with helical blade. 


\section{Model and data treatment}

\subsection{Nauta blender}

The Nauta blender consists of a conical stationary body and a screw impeller, as shown in Fig. 1. The screw sweeps the inclined wall and rotates around its axis at the same time. In this study, these two rotations are defined as sweeping rotation and primary rotation, respectively. Dimensions of this blender, listed in Table 1, were chosen based on a MIKRONS® 250-Liter Nauta blender. The total volume and filled volume of this blender are 251.5 and 137.9 liters, respectively. The top and bottom radii of the conical body were 0.56 and $0.11 \mathrm{~m}$, respectively, and the initial fill height was $0.34 \mathrm{~m}$ in simulations.

\subsection{DEM model}

The soft sphere method was utilized to describe the dynamics of particles in the blender. Governing equations of the DEM are as follows:

$$
\begin{aligned}
& m_{i} \frac{d v_{i}}{d t}=\sum_{j}\left(F_{i j}^{N}+F_{i j}^{T}\right)+m_{i} g \\
& I_{i} \frac{d \omega_{i}}{d t}=\sum_{j} M_{i j}^{T}+M_{i j}^{r}
\end{aligned}
$$

where $g, t, F$, and $M$ are gravity, time, force and torque, and $m_{i}, v_{i}, \omega_{i}$ and $I_{i}$ are mass, velocity, angular velocity and moment of inertia of particle $i$, respectively. The Hertzian contact model [33] was used for contact force:

$$
\begin{aligned}
& F^{N}=\left[\left(-\frac{4}{3} E_{e f f} \sqrt{r_{e f f}} \delta_{N}^{3 / 2}\right)-\left(\tilde{\eta}_{N} \delta_{N}^{1 / 4} v_{r N}\right)\right] n_{i j} \\
& F^{T}=-\frac{16}{3} G_{e f f} \sqrt{r_{e f f}} \delta_{N}^{1 / 2} \delta_{T} t_{i j}
\end{aligned}
$$

with 


$$
\begin{aligned}
& E_{\text {eff }}=\frac{1}{\left(\frac{1-v_{i}^{2}}{E_{i}}+\frac{1-v_{j}^{2}}{E_{j}}\right)} \\
& G_{e f f}=\frac{1}{\left(\frac{2-v_{i}}{G_{i}}+\frac{2-v_{j}}{G_{j}}\right)} \\
& r_{e f f}=\frac{1}{\left(\frac{1}{r_{i}}+\frac{1}{r_{j}}\right)}
\end{aligned}
$$

where $\tilde{\eta}_{N}, r, \delta, G, E, v, n_{i j}$ and $t_{i j}$ are, respectively, damping coefficient in normal direction, radius of particle, overlap, shear modulus, Young's modulus, Poisson's ratio and normal and tangential vectors. If $\left|F_{i j}^{T}\right| \geq \mu\left|F_{i j}^{N}\right|$, the Coulomb's criterion is violated, gross sliding happens and the tangential overlap is limited to [33]:

$$
\delta_{T}=\operatorname{sgn}\left(\delta_{T}\right) \frac{\mu\left|F_{i j}^{N}\right|}{k_{T}}
$$

where $\mu$ is the friction coefficient, and

$$
k_{T}=\frac{16}{3} G_{e f f} \sqrt{r_{e f f} \delta_{N}}
$$

The tangential torque is defined by:

$$
M_{i j}^{T}=r_{i} n_{i j} \times F_{i j}^{T}
$$

and the following equation was used to evaluate the rolling friction torque:

$$
M_{i j}^{r}=-\mu_{r} r_{i}\left|F_{i j}^{N}\right| \frac{\omega_{i}-\omega_{j}}{\left|\omega_{i}-\omega_{j}\right|}
$$

where $\mu_{\mathrm{r}}$ and $\omega$ are rolling friction factor and angular velocity of particle, respectively. The DEM open source code LIGGGHTS was used to solve the above mentioned equations for a 
system of spherical particles. LIGGGHTS is a DEM simulation code which consists of public and commercial sections and was initially developed by Kloss et al. [34].

\subsection{Data treatment}

Granular temperature is defined as the mean square of velocity fluctuations of particles and is calculated by:

$$
\theta=\frac{1}{3}\left[\overline{U_{x}^{\prime 2}}+\overline{U_{y}^{\prime 2}}+\overline{U_{z}^{\prime 2}}\right]
$$

in which $U_{i}{ }^{\prime}$ is the local velocity fluctuation in $i$ direction [35]. Value of the granular temperature has a significant role in the mixing, segregation and attrition of systems handling particles [35]. To calculate the granular temperature inside the Nauta blender, the system was divided into $27000(30 \times 30 \times 30)$ hexagonal $0.02-\mathrm{m}$ cells in this work. For choosing the proper cell size, four different sizes $(0.01,0.02,0.03$ and $0.04 \mathrm{~m}$ for each cell dimension) were tested to check the effect of cell size on the simulation results. It was found that decreasing the cell size from 0.04 to $0.02 \mathrm{~m}$ influenced the results, while with further decreasing the cell size to $0.01 \mathrm{~m}$, no significant difference was detected. Therefore, the cell size of $0.02 \mathrm{~m}$ was chosen for the post-processing. For this size of the cell, it was assured that enough number of particles (at least 25 particles) were in each sample and the sampling was not biased. In each cell, the velocity (volume-averaged velocity) and velocity fluctuations of particles were calculated. Using the velocity fluctuations, the granular temperature in the cell was calculated based on Equation (12) in each instant.

The Lacey mixing index (L.I.) was used for representing the mixing quality. This index is defined as [36]: 


$$
\text { L.I. }=\frac{\sigma_{0}^{2}-\sigma^{2}}{\sigma_{0}^{2}-\sigma_{R}^{2}}
$$

where $\sigma^{2}$ is the variance of samples gathered from the whole mixture and $\sigma_{0}^{2}$ and $\sigma_{R}^{2}$ show the variance of the complete segregated case (upper limit) and variance of the random mixture (lower limit) in a two-component mixture, respectively. They are defined by:

$$
\begin{gathered}
\sigma_{0}^{2}=p(1-p) \\
\sigma_{R}^{2}=\frac{p(1-p)}{n}
\end{gathered}
$$

where $p$ is the proportion of particles in each cell and $n$ is the average number of particles in the sample. A procedure, similar to that for calculating average velocity, and the cell size of $0.02 \mathrm{~m}$ was used for calculating the mixing index. At each time step, the proportion of particles (particles were marked based on their initial position in the blender) was calculated in each cell and the Lacey index was calculated based on these proportions. To characterize the mixing progress and comparing the mixing trends for different cases, the Lacey index was fitted on the following equation [37]:

$$
\text { L.I. }=1-e^{-k t}
$$

where $k$ is the mixing rate constant.

\section{Results and discussion}

\subsection{Validation of the model}

As mentioned before, there are no experimental data on the Nauta blender which can be used for validating the DEM results. Available experiments contain several hundred millions of particles which makes it infeasible for DEM simulations. Therefore, experimental data on a conical helical-blade blender were used in this work for validating the DEM results. 
Operation and geometry of the blender are very close to the Nauta blender considered in this work since the container in both blenders is conical and the rotation of a helical blade causes the main convective motion in both blenders. Results of the DEM model were compared with the experimental data in terms of mixing kinetics and particle velocity distribution in a conical helical-blade blender. This blender consists of a conical body (similar to the blender body used in this research) and the impeller is a helical blade which rotates clockwise. Schematic and sizes of the impeller and body of the blender can be found in [38]. The velocity profile and mixing kinetics were obtained by PEPT measurements [38]. Green peas with the diameter of $9.4 \mathrm{~mm}$ were used in the experiments. Simulation parameters (gathered from [38]) are listed in Table 2.

Entropy of mixing was calculated based on the number of rotations of the impeller. This entropy is defined as [38]:

$$
S=\frac{1}{S_{0}} \sum\left(x_{1}(i, j, k) \log \left(x_{1}(i, j, k)\right)+x_{2}(i, j, k) \log \left(x_{2}(i, j, k)\right)\right) \frac{N_{\text {cell }}(i, j, k)}{N}
$$

where $S, S_{0}, x, N$ and $N_{\text {cell }}$ are entropy of mixing, entropy of completely mixed system, composition of particles, total number of particles in the blender and number of particles in each cell, respectively, and $i, j$ and $k$ indicate the cell indices in the 3D space. It should be mentioned that the size of cells in the experiments and DEM was the same and equal to twice the size of a particle.

Fig. 2 shows the velocity vectors obtained from PEPT and DEM simulations. It can be seen in this figure that the DEM can accurately predict the experimental values. Upward flow near the blender wall, downward flow at the center of the blender, circulation pattern and semi- 
stagnant zone in blender were all well captured by the DEM. Magnitude of the velocity of particles in the DEM is also in good agreement with the experimental values. Using DEM simulations in this research, the evolution of the mixing entropy was also obtained and compared with experimental data in Fig. 3. This figure demonstrates that the DEM predicts the evolution of the mixing entropy very well.

\subsection{Nauta blender simulation results}

The DEM was next utilized to study the flow pattern of particles and their mixing performance in a Nauta blender. Simulation parameters and operating conditions are given in Table 3. Particles and walls in the simulation were assumed to be glass beads and steel, respectively. Required simulation parameters for these materials were obtained from [39]. Particles were first inserted into the blender from top through a virtual insertion box and were allowed to be packed with the gravity. In the packing stage, the screw was not moving. After the insertion step, the screw impeller began to sweep and rotate. The sweeping rotation of the impeller (changing from 0.15 to $0.3 \mathrm{rad} / \mathrm{s}$ ) around the blender body was anticlockwise while rotation of the impeller body around its axis (changing from 5 to $10 \mathrm{rad} / \mathrm{s}$ ) was clockwise. The impeller diameter also changed in the range of 9.72 to $10.8 \mathrm{~cm}$. Details of simulation conditions are given in Table 4.

The mixing progresses of red and gray particles, which are laterally filled in the blender at different operating conditions of cases 1, 2 and 3, are shown in Fig. 4. It can be seen in this figure that the height of particles near the impeller is always higher than in other regions of the blender. In other words, the free surface rises where the impeller exists and falls in the opposite side of the blender. This pattern was also observed by Fan and Chen [28] and van 
den Bergh and Scarlett [32]. Since the sweeping rotation is anticlockwise, the screw agitates the red particles initially which leads to higher level of particle in this region. Consequently, the red particles cascade on the free surface to the other side of the blender (the region with gray particles). As time passes, the gray particles are drawn into the flights of screw in the bottom of the blender and are lifted due to the wedging effect of screw and then appear on the surface of the bed. Since the screw sweeps the perimeter of the shell, the location at which particles are drawn in and discharged from the flights changes continuously. After 60 seconds, red and gray particles are almost well mixed for all the cases shown in Fig. 4.

\subsection{Solid flow pattern and mixing mechanism}

\subsubsection{Velocity profile of particles}

To better illustrate the 3D flow of particles, velocity vectors of particles on a vertical and a horizontal plane crossing the blender are shown in Fig. 5a and 5b. In these figures, the sweeping velocity, primary rotation velocity and the impeller diameter are $0.3 \mathrm{rad} / \mathrm{s}, 7.5 \mathrm{rad} / \mathrm{s}$ and $10.8 \mathrm{~cm}$, respectively. Arrows in this figure demonstrate the local volume-averaged velocity of particles. Rotation of the screw produces two distinct convective flows: bottomtop-bottom and tangential. In the bottom-top-bottom motion (as shown in Fig. 5a), particles at the bottom of the cone are drawn toward the impeller and transported to the free surface due to the primary rotation of impeller. At the top of the screw, particles exit the impeller and avalanche on the free surface of the bed. Particles move toward the impeller through the four lowest flights of the screw and exit it from the two top flights from the bed surface. To complete the bottom-top-bottom motion, particles flow downward due to the gravity on the opposite side of the impeller. This phenomenon creates a vertical circulation pattern in the Nauta blender. In fact, the primary rotation of impeller produces a convective and layered 
flow (will be shown later) in which particles are lifted to the bed surface and then descend at the opposite side of the screw. A semi-stagnant zone (very low particle velocities) near the cone axis is also developed in the middle of this circulation.

Fig. $5 \mathrm{~b}$ shows that there is a tangential flow due to sweeping rotation of the impeller. This motion pushes the particles along the direction of sweeping and induces this tangential flow. The magnitude of this flow falls to zero as moving away from the impeller in the direction of sweeping. Particles also move toward the impeller to hold the continuity of flow and to compensate the lack of particles in the region behind the impeller (upwind of sweeping motion).

The vertical circulation and the tangential flow are combined in the Nauta blender and led to a strong three dimensional flow in this blender. It also should be noted that the semi-stagnant zone is off-axis. This region is highlighted in Fig. 5a as an oval whose axis is parallel to the screw axis and is not located on the conical blender axis. This oval zone is not fixed and rotates with the sweeping rotation of the screw. Consequently, no permanent stagnant zone exists in the Nauta blender. The mixing pattern of particles, shown in Fig. 4, confirms the above described flow pattern. Gray particles located on the opposite side of the impeller are drawn toward the impeller at the cone bottom and are mixed with red particles during the lifting to the free surface. As a result, a strong mixing occurs in the hypothetical vertical plane (similar to the vertical plane observed in Fig. 5a) crossing the impeller axis. This hypothetical plane rotates as fast as the sweeping rotation of the impeller and sweeps the whole blender. This flow pattern produces a strong mixing in the blender and mixing is almost complete after 60 seconds. In cases 1, 2 and 3 of Fig. 4, the screw sweeps the 
perimeter of the blender body 1.43, 2.87 and 4.30 times, respectively, in 60 seconds. Although a slight difference in the mixing quality can be observed in these figures, it seems that the speed of sweeping rotation weakly affects the mixing rate. This will be more discussed in the following sections.

\subsubsection{Granular temperature}

There are two mixing mechanisms in a Nauta blender: convection and dispersion. As mentioned before, the granular temperature is a measure of local particle fluctuations with respect to the local average flow. A high granular temperature is an indication of intense particle agitation (random dispersive motion) while a low granular temperature shows a nonrandom bulk flow of particles [40]. Fig. 6 shows contours of the granular temperature of particles on a vertical plane crossing the impeller axis at sweeping velocity of $0.3 \mathrm{rad} / \mathrm{s}$, primary rotation velocity of $7.5 \mathrm{rad} / \mathrm{s}$ and impeller diameter of $10.8 \mathrm{~cm}$. This figure demonstrates that the particles located near the impeller are more agitated as a result of rotation of the impeller. In other words, impeller region has the highest granular temperature, indicating that the dispersive mixing is dominant in this region. Convective mixing is dominant in the remaining parts of the blender.

\subsubsection{Streamlines of particles}

The bottom-top-bottom flow in the Nauta blender is layered. This layered flow can be identified using streamlines of flow of particles. Streamlines of two groups of particles, initially located in the middle of the impeller zone and near the surface, are drawn in Fig. 7 at sweeping velocity of $0.3 \mathrm{rad} / \mathrm{s}$, primary rotation velocity of $7.5 \mathrm{rad} / \mathrm{s}$ and impeller diameter of $10.8 \mathrm{~cm}$. It should be noted that for drawing the streamlines, position of particles were traced 
before and after (two-way integrated streamlines) their initial location shown in Fig 7. This figure proves that the adjacent particles in each section move in parallel trajectories. It can be seen in Fig. 7a that some streamlines are divided into multiple distinct streamlines upon reaching the impeller. This suggests that the impeller breaks the major streamlines into secondary streamlines. In order to make this point clear, let's pursue a streamline in Fig. 7a which starts from the free surface, passes near the blender body and enters the impeller region at the bottom. After entering the impeller region, the streamline breaks into two distinct streamlines: one exits from the impeller region while the other rises up the impeller. On the contrary, the streamlines in Fig. $7 b$ keep their integrity in the impeller region during the

tracing. It should be mentioned that these two groups of streamlines (shown in Figs. 7a and 7b) are only samples of multiple similar streamlines that have similar behaviors in the blender. In general, by comparing Figs. 7a and b, it can be concluded that the impeller shows contrasting behavior toward the particle streamlines in its active region and there is a probability that the groups of particles keep their integrity in the impeller active region. This conclusion is also consistent with the granular temperature distribution in the blender, illustrated in Fig. 6.

\subsubsection{Tracer tests}

To reach a deeper understanding of flow pattern in the Nauta blender and support the observed flow pattern and mixing mechanisms, seven spherical groups of adjacent particles (each group contains 100-120 particles) were marked and their shape and positions were tracked during operation of the blender. For this purpose, particles located inside each of the seven hypothetical spheres (radius of hypothetical spheres was $0.025 \mathrm{~m}$ ) at $t=1.1 \mathrm{~s}$ after start of simulation, were marked with different colors. These marked particles were then tracked in 
time to observe their deformation/dispersion. Fig. 8 shows the initial position of tracers and their conditions during the blender operation. As can be seen in this figure, groups 6 and 7 are initially located in the convective zone while groups 1-4 are in the impeller region and group 5 is in the semi-stagnant zone. As mentioned above, the tracking started at 1.1 seconds after the start of the operation. At $t=1.4 \mathrm{~s}$, tracer groups 1, 2, 3 and 4 (those located initially inside the impeller region) are lifted by the impeller primary rotation. At a longer elapsed time, the impeller transports these three groups near the free surface. Tracer groups 6 and 7 are dragged downward since a downward flow exists in that region due to bottom-top-bottom motion. Tracer group 5, in the semi-stagnant zone, moves very slowly and is intact until $t=$ 3.6 s. Once this group of particles enters the impeller active region (the region in which agitation of particles is strong due to the presence of impeller) at $t=4.1 \mathrm{~s}$, it starts to deform. Finally, at $t=4.6 \mathrm{~s}$, all the tracer groups are deformed due to sweeping and primary rotations of the impeller. However, the degree of deformation and agitation of each group strongly depends on their initial position. Groups 1-4 are more deformed than groups 6 and 7 and group 5 is deformed the least.

\subsection{Mixing kinetics}

\subsubsection{Effect of primary rotation speed}

Three primary rotation speeds $\left(\omega_{\mathrm{a}}=5,7.5\right.$ and $\left.10 \mathrm{rad} / \mathrm{s}\right)$ at a constant impeller sweeping speed $\left(\omega_{\mathrm{s}}=0.3 \mathrm{rad} / \mathrm{s}\right)$ were considered (cases 4,2 and 5 , respectively) to study the effect of primary rotation speed on the mixing. Evolutions of the Lacey index for these three cases are illustrated in Fig. 9. This figure shows that the rate of mixing increases with increasing the primary rotation speed. The exponential decay model was also fitted on the Lacey index and mixing rate constants and coefficients of determination are also given on the figure. 
According to Fig. 9, the mixing rate constantly increases by increasing the primary rotation speed (i.e., better mixing). By increasing the primary rotation speed, the impeller can lift more particles to the free surface in a specific period of time. As a result, circulation of particles requires shorter time to be completed which leads to a better mixing quality and a greater mixing index.

To verify the increasing trend of Lacey index and mixing rates against the primary velocity, granular temperature distributions of particles are compared for cases 4,2 and 5. Since the primary rotation speed and impeller diameter directly affect the active region of impeller, by comparing the number of particles at each granular temperature level, the agitation quality of particles in each case can be revealed. Particles with a granular temperature more than 0.002 $\mathrm{m}^{2} / \mathrm{s}^{2}$ were selected for this comparison. This threshold filters out the particles which are not influenced by the impeller (see Fig. 6). Distribution of granular temperature of particles at various primary rotation speeds for particles with a granular temperature greater than 0.002 $\mathrm{m}^{2} / \mathrm{s}^{2}$ is shown in Fig. 10. It can be seen in this figure that on average, the granular temperature increases by increasing the primary rotation velocity. The range of distribution is widened and the frequencies of granular temperatures are almost increased except the frequencies in the range between 0.06 and 0.08 . This range of granular temperature mostly belongs to the particles near the axis of the blender. In this region, particle motions are less directly affected by the impeller speed. As shown before, the majority of local fluctuations occur in the impeller region due to motion of impeller. As the primary rotation speed increases, more particles become intensely influences by the impeller and the distribution of granular temperature shifts toward greater values. Higher granular temperature means that particles are more agitated in the blender and the mixing is faster. It can be concluded that 
there are two reasons behind increasing the mixing rate with increasing the primary rotation speed: faster circulation of particles in the blender, and higher agitation of particles in the impeller active region.

\subsubsection{Effect of sweeping speed}

Three impeller sweeping speeds $\left(\omega_{\mathrm{s}}=0.15,0.3\right.$ and $\left.0.45 \mathrm{rad} / \mathrm{s}\right)$ at a constant primary rotation speed $\left(\omega_{\mathrm{a}}=7.5 \mathrm{rad} / \mathrm{s}\right)$ were considered to investigate the effect of sweeping speed on the mixing of solids. Fig. 11 shows the evolution of Lacey index during the operation of the blender at various sweeping speeds. This figure shows that the mixing rate slows down with increasing the sweeping speed. Comparing Fig. 11 with Fig. 9 also reveals that the influence of primary rotation speed on the Lacey index is more than that of the sweeping speed. The exponential decay model was also fitted to the mixing index curves and mixing rate constants (k) are given on Fig. 11. It can be seen in this figure that by increasing the sweeping velocity, the mixing rate constant becomes smaller. For explaining this trend, three tracer groups were placed initially in the middle of the blender body axis (see Fig. 8) and were followed in time. Due to small differences between Lacey indices of cases 2 and $3\left(\omega_{\mathrm{s}}=0.3,0.45 \mathrm{rad} / \mathrm{s}\right.$, respectively), only cases 1 and $2\left(\omega_{\mathrm{s}}=0.15,0.3 \mathrm{rad} / \mathrm{s}\right.$, respectively) are compared. Fig. 12 shows the motion of three groups of tracer particles (groups 1, 2 and 3 in Fig. 8) for cases 1 and 2 at $t=2.6 \mathrm{~s}$. It can be seen in this figure that in case $1\left(\omega_{\mathrm{s}}=0.15 \mathrm{rad} / \mathrm{s}\right)$, the impeller lifts the tracers to the free surface while in case $2\left(\omega_{\mathrm{s}}=0.3 \mathrm{rad} / \mathrm{s}\right)$ the particles exit the impeller from behind as the impeller sweeps the blender. This shows that by increasing the sweeping speed, particles in the flights of the impeller leave the impeller quicker and are not transported to the surface of the bed which leads to two negative effects: first, the bottom-top- 
bottom motion (which is essential for mixing) is disturbed and second, the agitation effect of the impeller is reduced since particles spend less time in this region.

To reach a deeper understanding about the effect of sweeping velocity $\left(\omega_{\mathrm{s}}\right)$ on the mixing quality, six extra simulations with six different sweeping velocities $\left(\omega_{s}=0.0,0.025,0.05\right.$, $0.075,0.1,0.15,0.3$ and $0.45 \mathrm{rad} / \mathrm{s}$ ) were performed and mixing rates in these cases were calculated. Fig. 13 shows the effect of sweeping velocity on the mixing rate. It can be seen in this figure that the maximum value of the mixing constant is obtained at $\omega_{\mathrm{s}}=0.05 \mathrm{rad} / \mathrm{s}$. For greater sweeping velocities, as described before, the particles fall out of the impeller before they reach the bed surface. At sweeping velocities less than $0.05 \mathrm{rad} / \mathrm{s}$, the impeller spends a long time in one location and locally mixes the nearby particles, which results in a poor global mixing. This optimum sweeping velocity can change with operating conditions, like primary rotation speed, particle loading level and blender geometry.

It also should be noted in Fig. 11 that in some instances the Lacey index in the blender with high sweeping velocity is greater than that with a lower sweeping velocity. As stated before, the overall mixing rate (with regard to the mixing constant, $k$ ) of particles decreases by increasing the sweeping velocity in the range reported in Fig.11. This is because the Lacey mixing index is very sensitive to particle concentration at initial stages of the mixing $($ L.I. < 0.7) and small changes in the particle concentration results in a large change in the Lacey index. 


\subsubsection{Effect of impeller diameter}

Effect of changing the impeller diameter $\left(\omega_{\mathrm{s}}=0.3 \mathrm{rad} / \mathrm{s}, \omega_{\mathrm{a}}=7.5 \mathrm{rad} / \mathrm{s}\right.$ and impeller diameters are $9.72,10.26$ and $10.8 \mathrm{~cm}$ ) on the mixing performance of the Nauta blender is shown in Fig. 14. This figure demonstrates that the Lacey index increases by increasing the impeller diameter. By decreasing the impeller diameter, fewer particles can be lifted up, which prevents the complete circulation of particles in the Nauta blender and consequently, decreases the mixing quality. Values of the mixing rate constant are also reported in Fig. 14 which shows that a greater rate constant is obtained as the impeller diameter increases. The range of change of the screw diameter in the simulations was limited by blender geometry and its cone angle. The blender geometry, cone angle and impeller geometry can also affect the mixing pattern and kinetics. This is a part of future studies in this field.

\section{Conclusions}

DEM simulations of Nauta blender were performed and flow patterns of particles in the blender were studied by means of investigating velocity distribution of particles in vertical and horizontal cross sections, granular temperature distribution, streamlines of particles and tracking tracer particle groups in the blender. The model was validated with experimental data of a convective conical screw blender and a good agreement was observed between experimental data and modeling results. It was shown that the free surface rises where the impeller is located and falls on the other side of the blender. The impeller conveys particles from the blender cone bottom to the free surface, where particles near the impeller roll down the free surface. Particles on the other side of the blender descend due to gravity. Consequently, a vertical circulation with a semi-stagnant zone at the center is observed in the Nauta blender. A tangential cross flow also exists in the direction of sweeping rotation of 
impeller. This cross flow vanishes as moving away from the impeller in the direction of sweeping. The combination of vertical circulation and horizontal cross flow shapes the three dimensional motion of particles in a Nauta blender. It was shown (by the granular temperature) that particles located near the impeller are more agitated due to sweeping rotation (rotation of impeller around the blender body) and primary rotation (rotation of impeller around its own axis) of the impeller. In the layers adjacent to the impeller, granular temperature is also high due to the rotating motion of the impeller. It was also found that the impeller breaks primary streamlines into secondary streamlines and this division can occur in all sections of the impeller. To better understand the flow pattern of particles in Nauta blenders, seven spherical groups of neighboring particles were marked and tracked during the operation of the blender and the results confirmed the observations from the streamlines and flow pattern of particles. Effects of sweeping speed, primary speed and diameter of impeller were investigated on the mixing performance of the blender (Lacey mixing index and mixing rate). It was observed that by increasing the sweeping speed (from 0.15 to $0.45 \mathrm{rad} / \mathrm{s}$ ) at a constant primary rotation speed $(7.5 \mathrm{rad} / \mathrm{s}$ ), the mixing rate constant decreases (from 0.04429 to $0.0313 \mathrm{1} / \mathrm{s}$ ) since particles in touch with the impeller become separated from the impeller before reaching the free surface which interrupts the mixing process. It was also shown that increasing the primary rotation speed (from 5 to $10 \mathrm{rad} / \mathrm{s}$ ) and impeller diameter (from 9.72 to $10.8 \mathrm{~cm}$ ) increase the mixing rate constant (from 0.02096 to $0.05321 / \mathrm{s}$ and from 0.02462 to $0.034651 / \mathrm{s}$, respectively) as well as the mixing index. For a better understanding of the effect of sweeping velocity on the mixing quality, six extra simulations at low sweeping velocities were performed and the maximum mixing rate was observed at primary rotation speed of $0.05 \mathrm{rad} / \mathrm{s}$. 


\section{Notation}

$D=$ diameter of impeller, $\mathrm{m}$

$d=$ diameter of particles, $\mathrm{mm}$

$E=$ Young's modulus, $\mathrm{Pa}$

$e=$ coefficient of restitution, dimensionless

$F_{i j}{ }^{N}=$ normal force, $\mathrm{N}$

$F_{i j}{ }^{T}=$ tangential force, $\mathrm{N}$

$G=$ shear modulus, $\mathrm{Pa}$

$g=$ gravity acceleration, $\mathrm{m} / \mathrm{s}^{2}$

$I=$ moment of inertia, $\mathrm{kg} \cdot \mathrm{m}^{2}$

$k=$ mixing rate constant, $1 / \mathrm{s}$

$L=$ axial height of blender body, $\mathrm{m}$

L.I. Lacey mixing index, dimensionless

$M_{i j}{ }^{T}=$ tangential torque, N.m

$M_{i j}{ }^{r}=$ rolling friction torque, N.m

$m=$ mass of particle, $\mathrm{kg}$

$N_{\text {cell }}=$ number of particles in a cell, dimensionless

$N=$ total number of particles in the blender, dimensionless

$n_{i j}=$ normal vector, dimensionless

$n=$ average number of particles in samples, dimensionless

$p=$ proportion of particles in each cell, dimensionless

$R^{2}=$ correlation coefficient, dimensionless

$R_{1}=$ upper diameter of the conical blender body, $\mathrm{m}$ 
$R_{2}=$ lower diameter of the conical blender body, $\mathrm{m}$

$r=$ radius of particles, $\mathrm{mm}$

$S_{0}=$ entropy of completely mixed system, dimensionless

$S=$ entropy of mixing, dimensionless

$t_{i j}=$ tangential vector, dimensionless

$U^{\prime}=$ fluctuating velocity, $\mathrm{m} / \mathrm{s}$

$v=$ velocity of particle, $\mathrm{m} / \mathrm{s}$

$x=$ fraction of the particles

\section{Greek letters}

$\delta=$ overlap of particles, $\mathrm{m}$

$\tilde{\eta}_{\mathrm{n}}=$ damping coefficient, $\mathrm{kg} / \mathrm{s} \cdot \mathrm{m}^{0.25}$

$\theta=$ granular temperature, $\mathrm{m}^{2} / \mathrm{s}^{2}$

$\mu=$ friction coefficient, dimensionless

$\mu_{\mathrm{r}}=$ rolling friction factor, dimensionless

$v=$ Poisson's ratio, dimensionless

$v_{\mathrm{rN}}=$ relative velocity of particle in normal direction, $\mathrm{m} / \mathrm{s}$

$\rho=$ density of particles, $\mathrm{kg} / \mathrm{m}^{3}$

$\sigma=$ standard deviation of samples, dimensionless

$\sigma_{0}=$ standard deviation of complete segregated mixture, dimensionless

$\sigma_{\mathrm{r}}=$ standard deviation of randomly mixed mixture, dimensionless

$\omega=$ angular velocity of particle, $\mathrm{rad} / \mathrm{s}$

$\omega_{\mathrm{a}}=$ primary rotation velocity, $\mathrm{rad} / \mathrm{s}$ 
$\omega_{\mathrm{s}}=$ sweeping velocity, $\mathrm{rad} / \mathrm{s}$

\author{
Subscripts and superscripts \\ $0=$ initial state \\ eff $=$ effective \\ $i, j=$ particles $\mathrm{i}$ and $\mathrm{j}$ \\ $N=$ normal direction \\ $r=$ random mixture \\ $T=$ tangential direction \\ $x, y, z=$ Cartesian vector components
}

\title{
References
}

[1] C. Wightman, F.J. Muzzio, Mixing of granular material in a drum mixer undergoing rotational and rocking motions I. Uniform particles, Powder Technology, 98 (1998) 113-124.

[2] C.-Y. Wu, DEM simulations of die filling during pharmaceutical tabletting, Particuology, 6 (2008) 412-418.

[3] B. Laurent, J. Bridgwater, Performance of single and six-bladed powder mixers, Chemical Engineering Science, 57 (2002) 1695-1709.

[4] E. Alizadeh, F. Bertrand, J. Chaouki, Comparison of DEM results and Lagrangian experimental data for the flow and mixing of granules in a rotating drum, AIChE Journal, 60 (2014) 60-75. 
[5] J. Jones, J. Bridgwater, A case study of particle mixing in a ploughshare mixer using Positron Emission Particle Tracking, International Journal of Mineral Processing, 53 (1998) 29-38.

[6] A. Munjiza, P.W. Cleary, Industrial particle flow modelling using discrete element method, Engineering Computations, 26 (2009) 698-743.

[7] H. Norouzi, R. Zarghami, N. Mostoufi, Insights into the granular flow in rotating drums, Chemical Engineering Research and Design, 102 (2015) 12-25.

[8] G. Chandratilleke, A. Yu, R. Stewart, J. Bridgwater, Effects of blade rake angle and gap on particle mixing in a cylindrical mixer, Powder Technology, 193 (2009) 303-311.

[9] M. Alian, F. Ein-Mozaffari, S.R. Upreti, Analysis of the mixing of solid particles in a plowshare mixer via discrete element method (DEM), Powder Technology, 274 (2015) $77-87$.

[10] M. Sakai, Y. Shigeto, G. Basinskas, A. Hosokawa, M. Fuji, Discrete element simulation for the evaluation of solid mixing in an industrial blender, Chemical Engineering Journal, 279 (2015) 821-839.

[11] G. Basinskas, M. Sakai, Numerical study of the mixing efficiency of a batch mixer using the discrete element method, Powder Technology, 301 (2016) 815-829.

[12] M. Alian, F. Ein-Mozaffari, S.R. Upreti, J. Wu, Using discrete element method to analyze the mixing of the solid particles in a slant cone mixer, Chemical Engineering Research and Design, 93 (2015) 318-329.

[13] B. Alchikh-Sulaiman, M. Alian, F. Ein-Mozaffari, A. Lohi, S.R. Upreti, Using the discrete element method to assess the mixing of polydisperse solid particles in a rotary drum, Particuology, 25 (2016) 133-142. 
[14] B. Alchikh-Sulaiman, F. Ein-Mozaffari, A. Lohi, Evaluation of poly-disperse solid particles mixing in a slant cone mixer using discrete element method, Chemical Engineering Research and Design, 96 (2015) 196-213.

[15] M. Yamamoto, S. Ishihara, J. Kano, Evaluation of particle density effect for mixing behavior in a rotating drum mixer by DEM simulation, Advanced Powder Technology, 27 (2016) 864-870.

[16] X. Hua, J. Curtis, B. Hancock, W. Ketterhagen, C. Wassgren, The kinematics of noncohesive, sphero-cylindrical particles in a low-speed, vertical axis mixer, Chemical Engineering Science, 101 (2013) 144-164.

[17] B. Remy, J.G. Khinast, B.J. Glasser, Discrete element simulation of free flowing grains in a four-bladed mixer, AIChE Journal, 55 (2009) 2035-2048.

[18] A. Hassanpour, H. Tan, A. Bayly, P. Gopalkrishnan, B. Ng, M. Ghadiri, Analysis of particle motion in a paddle mixer using Discrete Element Method (DEM), Powder Technology, 206 (2011) 189-194.

[19] J. Li, C. Wassgren, J.D. Litster, Multi-scale modeling of a spray coating process in a paddle mixer/coater: the effect of particle size distribution on particle segregation and coating uniformity, Chemical Engineering Science, 95 (2013) 203-210.

[20] Y. Tsuji, T. Kawaguchi, T. Tanaka, Discrete particle simulation of two-dimensional fluidized bed, Powder Technology, 77 (1993) 79-87.

[21] H. Norouzi, N. Mostoufi, Z. Mansourpour, R. Sotudeh-Gharebagh, J. Chaouki, Characterization of solids mixing patterns in bubbling fluidized beds, Chemical Engineering Research and Design, 89 (2011) 817-826. 
[22] K.T. Lee, A. Ingram, N.A. Rowson, Comparison of granule properties produced using Twin Screw Extruder and High Shear Mixer: A step towards understanding the mechanism of twin screw wet granulation, Powder Technology, 238 (2013) 91-98.

[23] L. Pezo, A. Jovanović, M. Pezo, R. Čolović, B. Lončar, Modified screw conveyormixers-Discrete element modeling approach, Advanced Powder Technology, (2015).

[24] M.L. Rathod, J.L. Kokini, Effect of mixer geometry and operating conditions on mixing efficiency of a non-Newtonian fluid in a twin screw mixer, Journal of Food Engineering, 118 (2013) 256-265.

[25] K.V. Vyakaranam, B.K. Ashokan, J.L. Kokini, Evaluation of effect of paddle element stagger angle on the local velocity profiles in a twin-screw continuous mixer with viscous flow using Finite Element Method simulations, Journal of Food Engineering, 108 (2012) 585-599.

[26] N. Harnby, The selection of powder mixers, Mixing in the Process Industries, (1992) 42 61.

[27] J.C. Williams, The mixing of dry powders, Powder Technology, 2 (1968) 13-20.

[28] L. Fan, Y.-M. Chen, F. Lai, Recent developments in solids mixing, Powder Technology, 61 (1990) 255-287.

[29] T. Yano, M. Sato, K. Terashita, Recent work in Japan on the mixing of solids, Powder Technology, 20 (1978) 9-14.

[30] P. Cook, J. Hersey, Evaluation of a Nauta mixer for preparing a multicomponent mixture, Powder Technology, 9 (1974) 257-261.

[31] O. Berntsson, L.-G. Danielsson, B. Lagerholm, S. Folestad, Quantitative in-line monitoring of powder blending by near infrared reflection spectroscopy, Powder Technology, 123 (2002) 185-193. 
[32] W. van den Bergh, B. Scarlett, Z. Kolar, Computer simulation model of a Nauta mixer, Powder Technology, 77 (1993) 19-30.

[33] Y. Tsuji, T. Tanaka, T. Ishida, Lagrangian numerical simulation of plug flow of cohesionless particles in a horizontal pipe, Powder Technology, 71 (1992) 239-250.

[34] C. Kloss, C. Goniva, A. Hager, S. Amberger, S. Pirker, Models, algorithms and validation for opensource DEM and CFD-DEM, Progress in Computational Fluid Dynamics, an International Journal, 12 (2012) 140-152.

[35] C.E. Brennen, Fundamentals of multiphase flow, Cambridge University Press2005.

[36] P.M.C. Lacey, Developments in the theory of particle mixing, Journal of applied chemistry, 4 (1954) 257-268.

[37] S. Gorji-Kandi, S. Alavi-Amleshi, N. Mostoufi, A solids mixing rate correlation for small scale fluidized beds, Particuology, (2014).

[38] M. Schutyser, W. Briels, A. Rinzema, R. Boom, Numerical simulation and PEPT measurements of a 3D conical helical-blade mixer: a high potential solids mixer for solid-state fermentation, Biotechnology and bioengineering, 84 (2003) 29-39.

[39] M. Liu, Y. Wen, R. Liu, B. Liu, Y. Shao, Investigation of fluidization behavior of high density particle in spouted bed using CFD-DEM coupling method, Powder Technology, 280 (2015) 72-82.

[40] M.J. Biggs, D. Glass, L. Xie, V. Zivkovic, A. Buts, M.C. Kounders, Granular temperature in a gas fluidized bed, Granular Matter, 10 (2008) 63-73. 


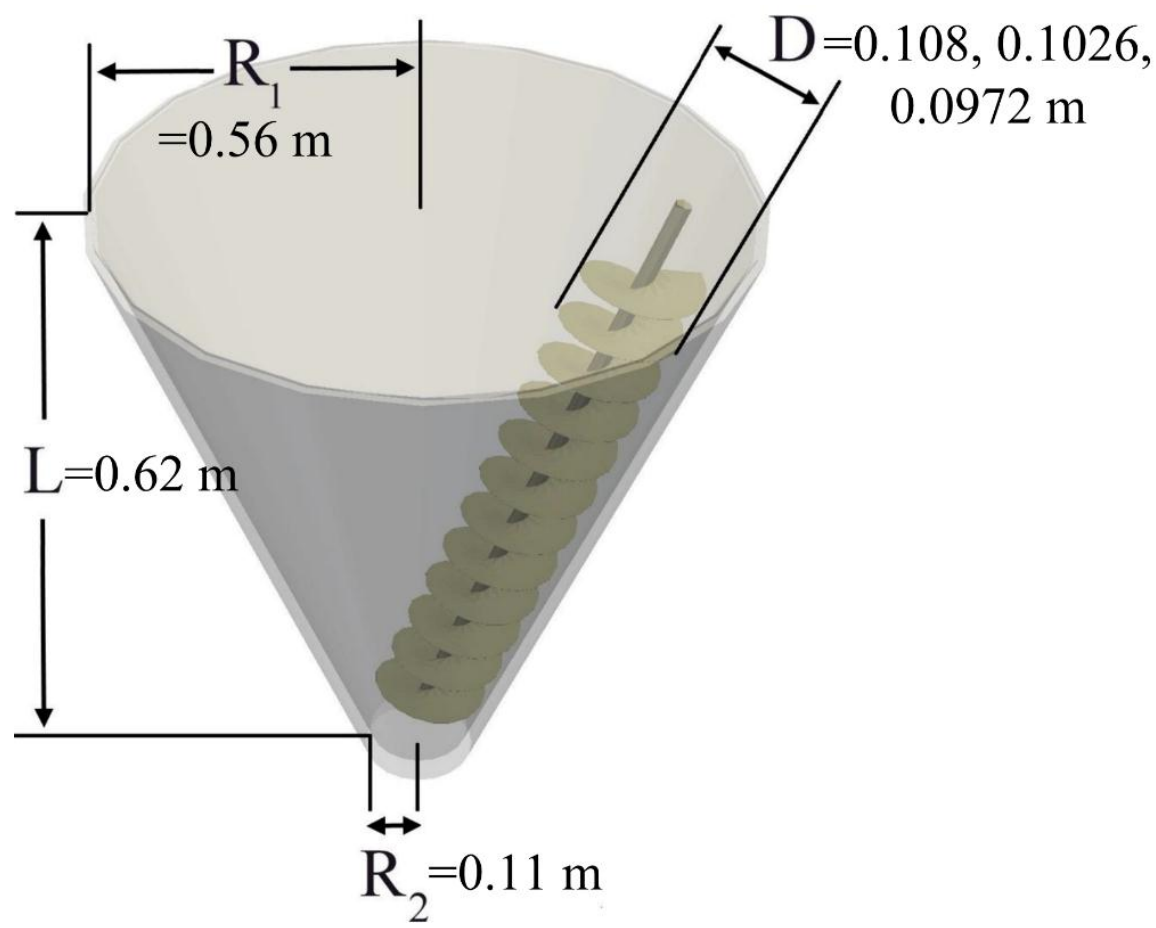

Fig. 1. Schematic of the Nauta blender body and screw impeller. 

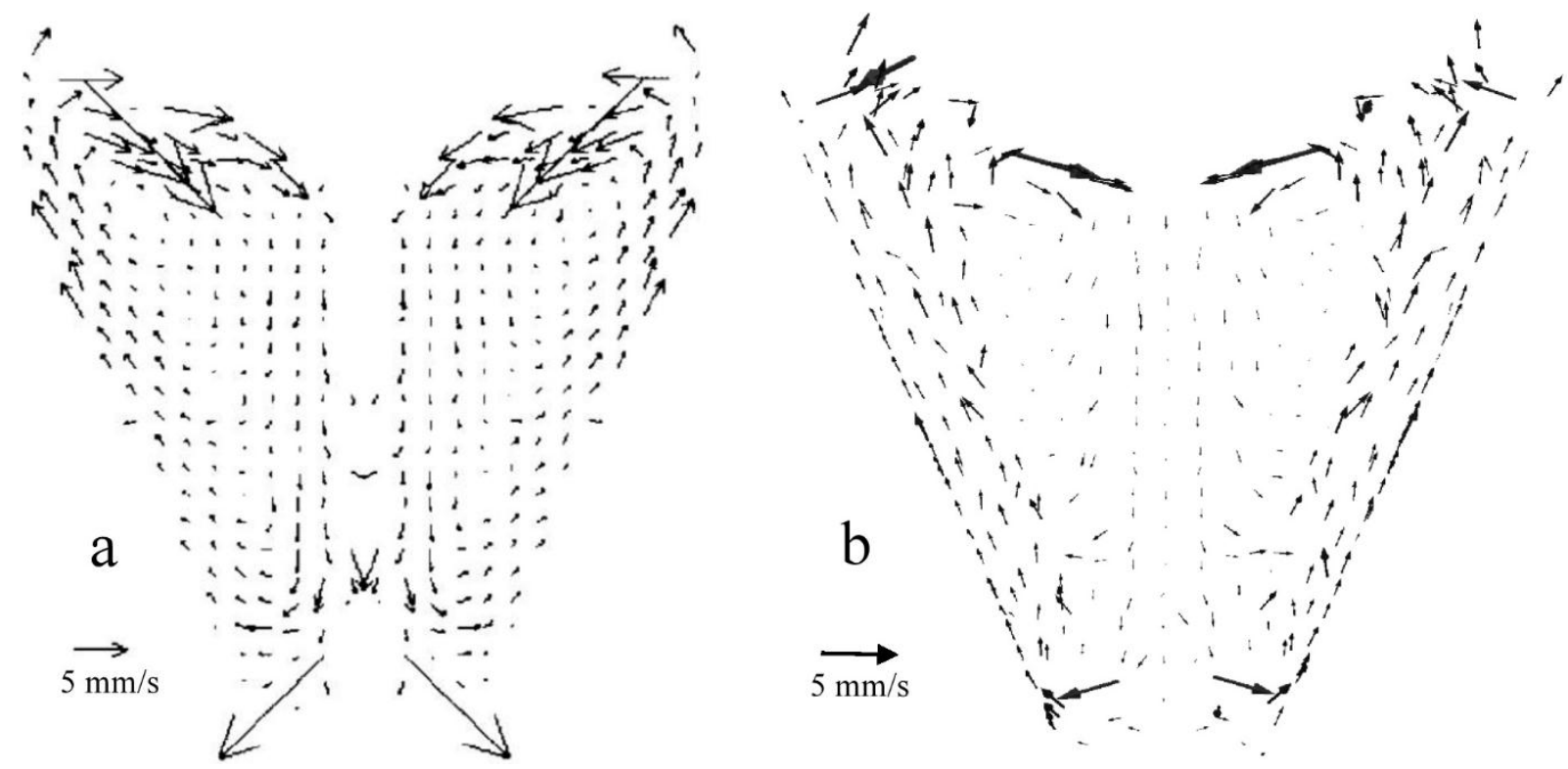

Fig. 2. Comparison of the time-averaged velocity vectors of the particles using (a) PEPT [38], and (b) DEM. 


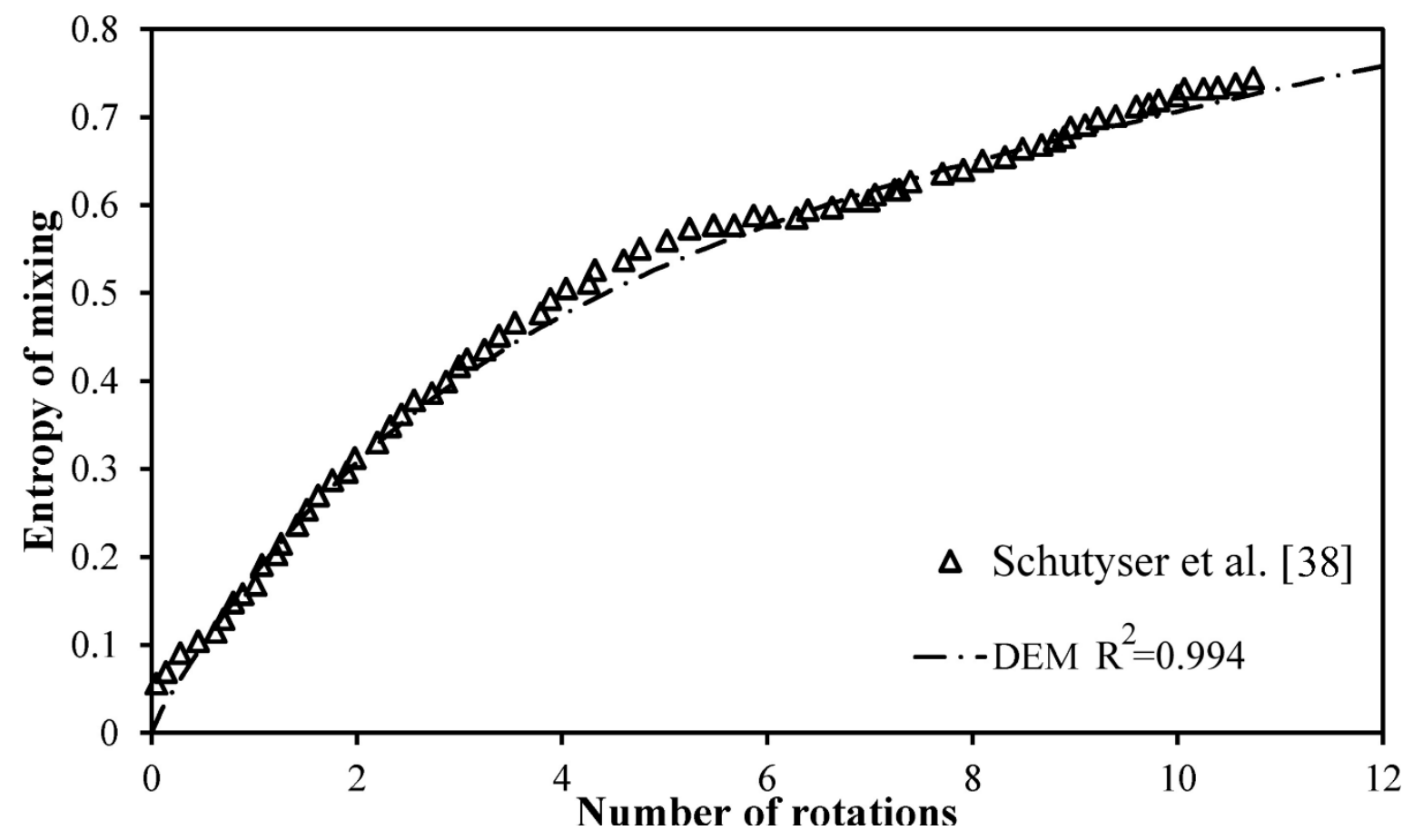

Fig. 3. Validation of the utilized DEM model with experimental results [38], using entropy of mixing at different impeller rotations. 


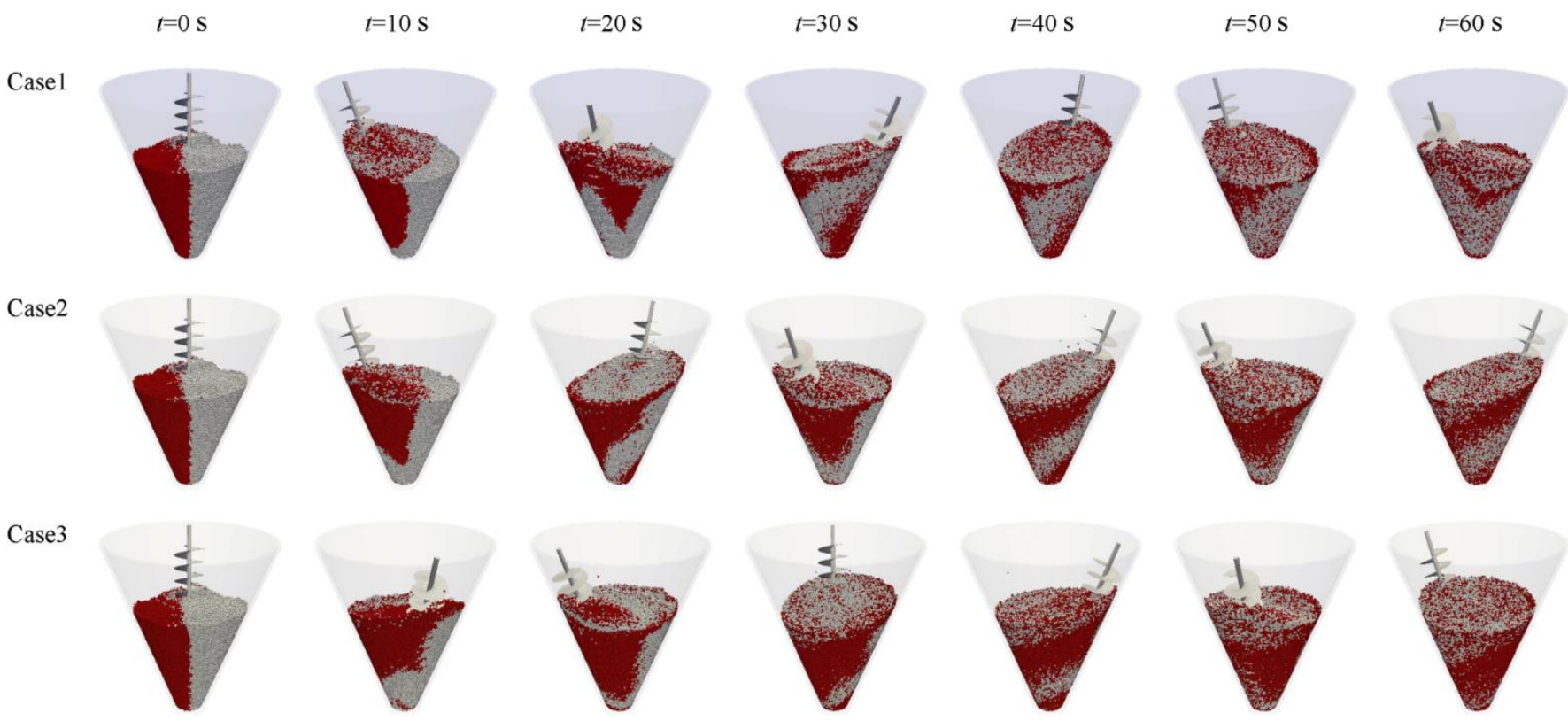

Fig. 4. Snapshots of the Nauta blender operation. Primary rotation velocity $=7.5 \mathrm{rad} / \mathrm{s}$, impeller diameter $=10.8 \mathrm{~cm}$ and sweeping velocity $=0.15,0.3$ and $0.45 \mathrm{rad} / \mathrm{s}$ for cases 1,2 and 3 , respectively. 

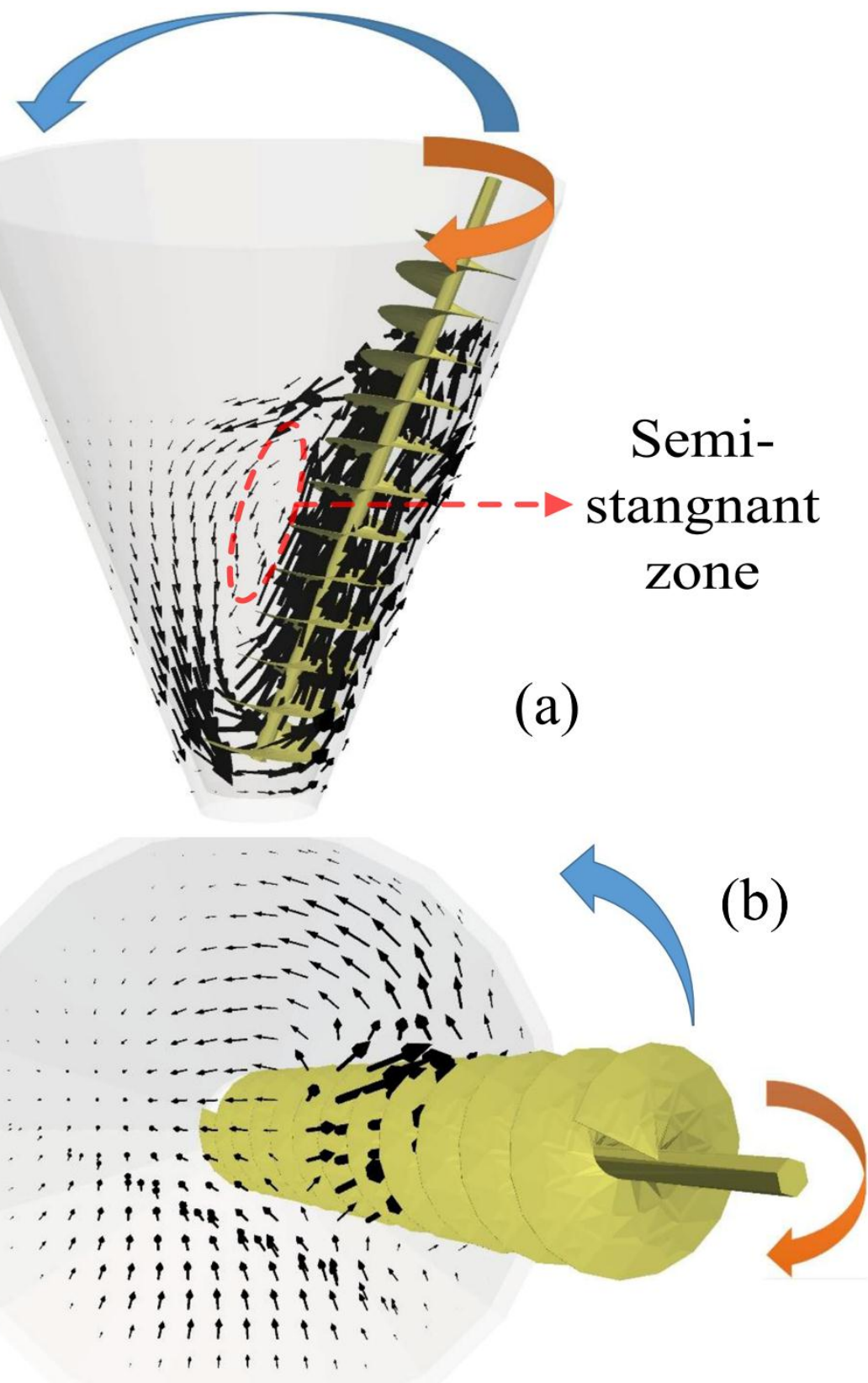

Fig. 5. Flow pattern of particles (a) vertical cross section in the middle of the blender (b) horizontal cross section near the free surface. The sweeping rotation is anticlockwise, while the primary rotation of impeller around its axis is clockwise. Sweeping velocity $=0.3 \mathrm{rad} / \mathrm{s}$, primary rotation velocity $=7.5 \mathrm{rad} / \mathrm{s}$ and impeller diameter $=10.8 \mathrm{~cm}$. 


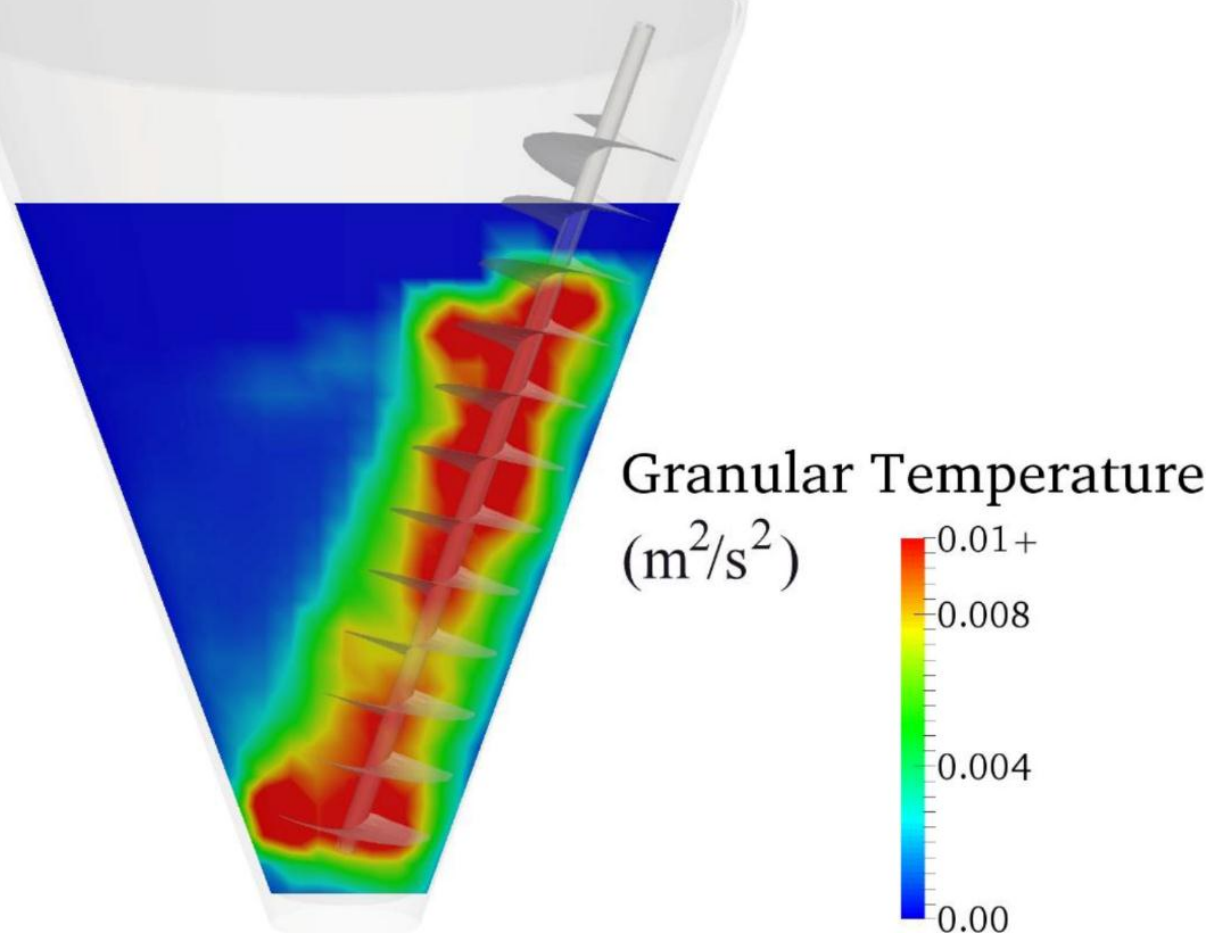

Fig. 6. Distribution of granular temperature in the Nauta blender. Regions with no particles and regions with static particles are both colored in blue. Sweeping velocity $=0.3 \mathrm{rad} / \mathrm{s}$, primary rotation velocity $=7.5 \mathrm{rad} / \mathrm{s}$ and impeller diameter $=10.8 \mathrm{~cm}$. 

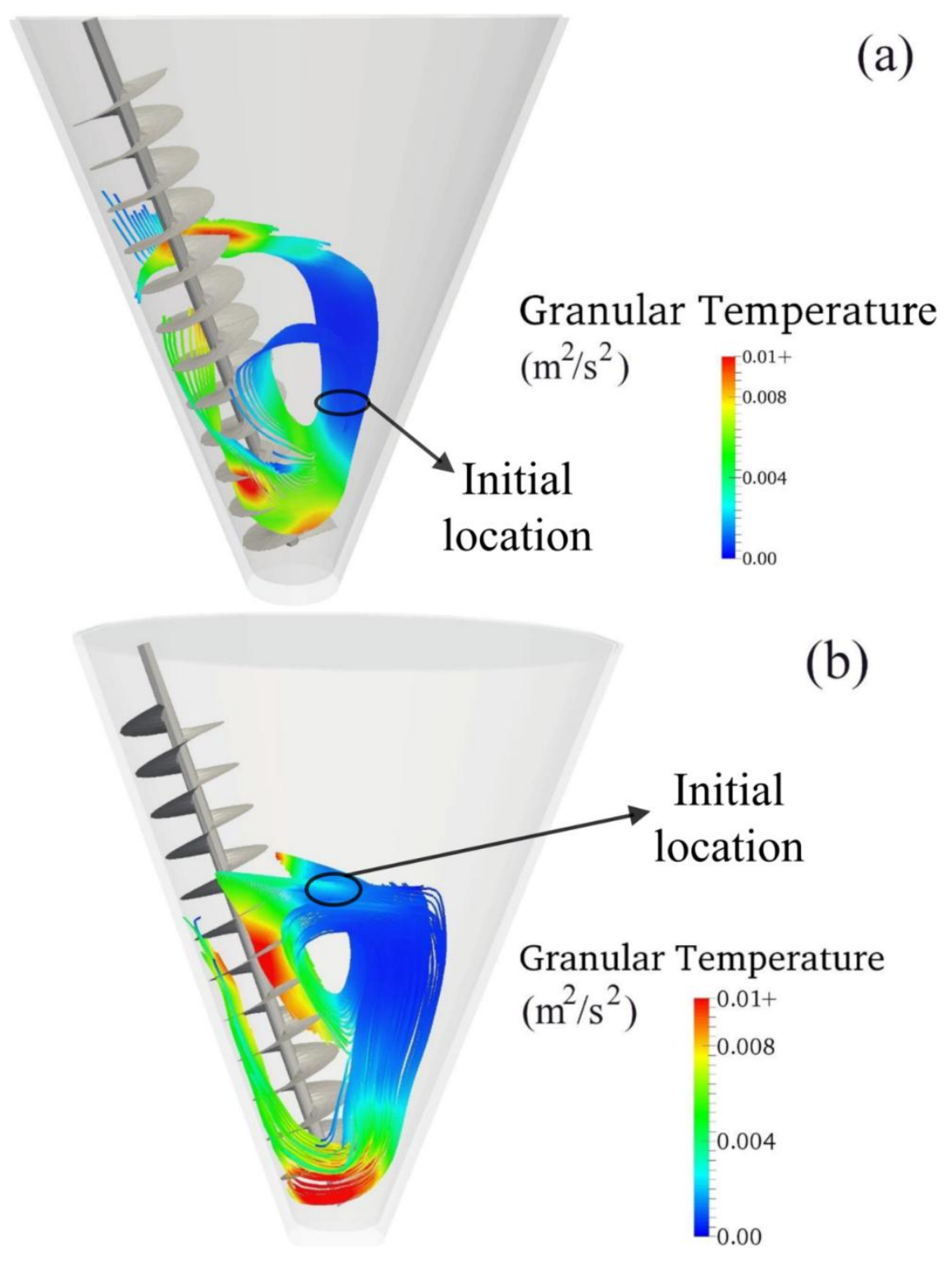

Fig. 7. Streamlines of two different groups of sample adjacent particles (a) located at the middle of the impeller, (b) located near the free surface. Sweeping velocity $=0.3 \mathrm{rad} / \mathrm{s}$, primary rotation velocity $=7.5 \mathrm{rad} / \mathrm{s}$ and impeller diameter $=10.8 \mathrm{~cm}$. 

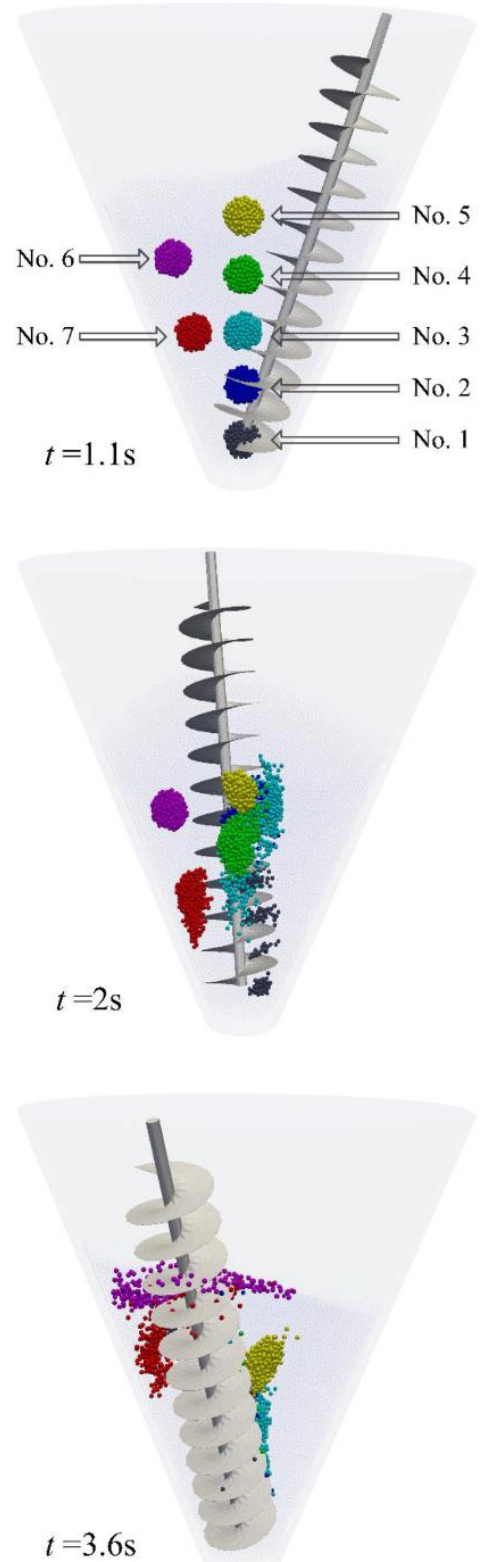
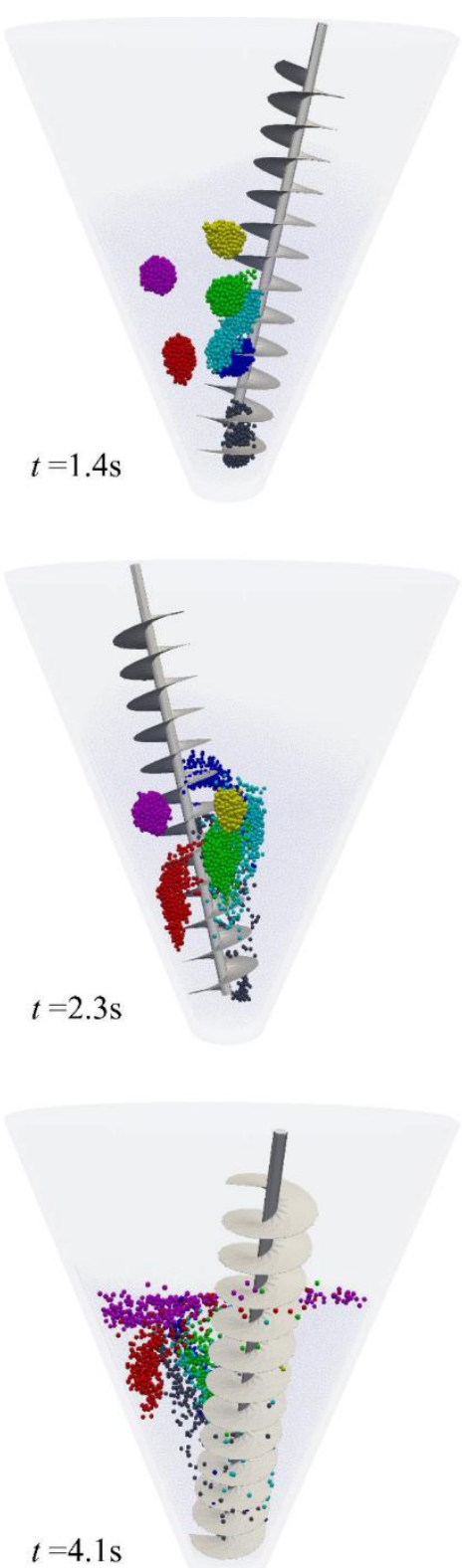
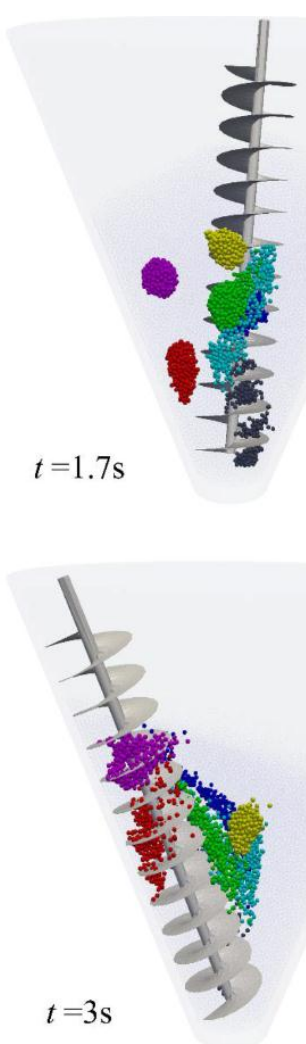

$t=3 \mathrm{~s}$

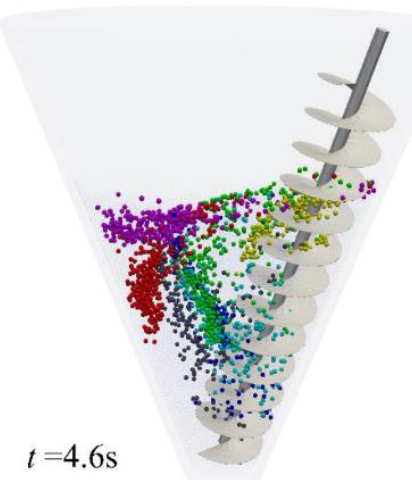

Fig. 8. Positions of tracers in the Nauta blender at different times. Sweeping velocity $=0.45$ $\mathrm{rad} / \mathrm{s}$, primary rotation velocity $=7.5 \mathrm{rad} / \mathrm{s}$ and impeller diameter $=10.8 \mathrm{~cm}$. 


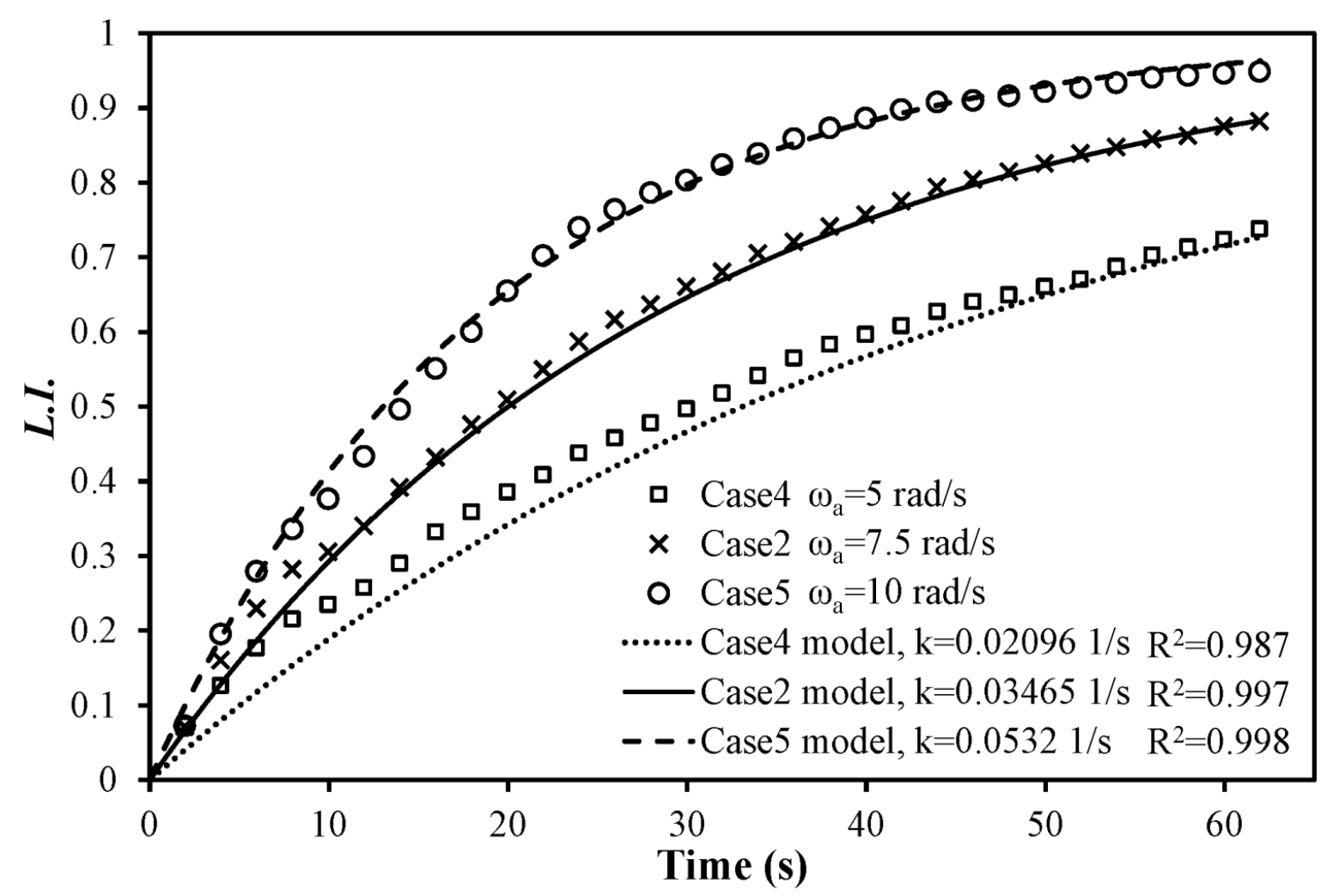

Fig. 9. Mixing index in Nauta blender as a function of time at various impeller primary rotation speeds. Sweeping velocity $=0.3 \mathrm{rad} / \mathrm{s}$ and impeller diameter $=10.8 \mathrm{~cm}$. 


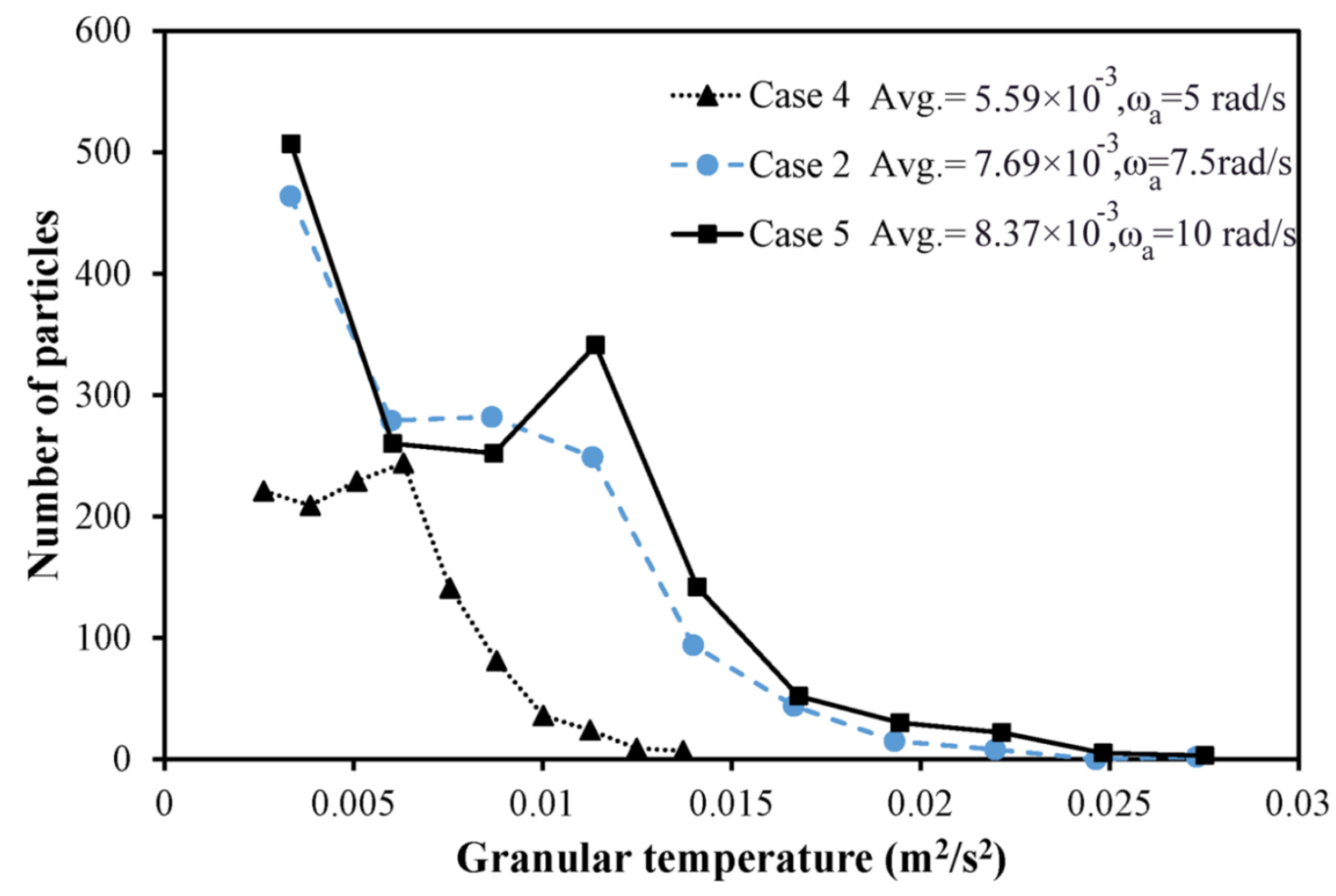

Fig. 10. Granular temperature distribution of particles in cases 4, 2 and 5. Sweeping velocity $=$ $0.3 \mathrm{rad} / \mathrm{s}$ and impeller diameter $=10.8$ 


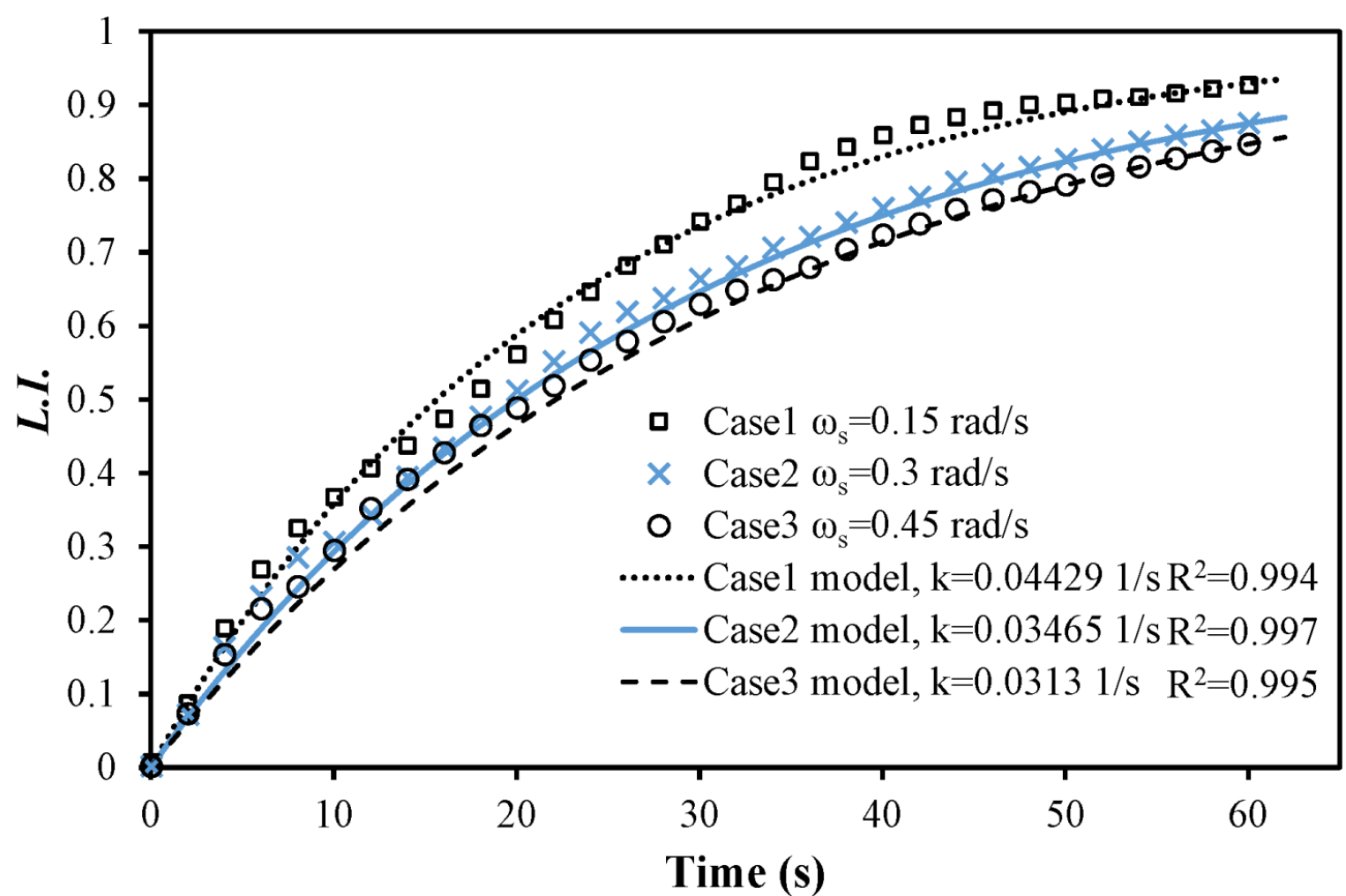

Fig. 11. Mixing index in Nauta blender as a function of time at various impeller sweeping speeds. Primary rotation velocity $=7.5 \mathrm{rad} / \mathrm{s}$ and impeller diameter $=10.8 \mathrm{~cm}$ at various sweeping velocities. 

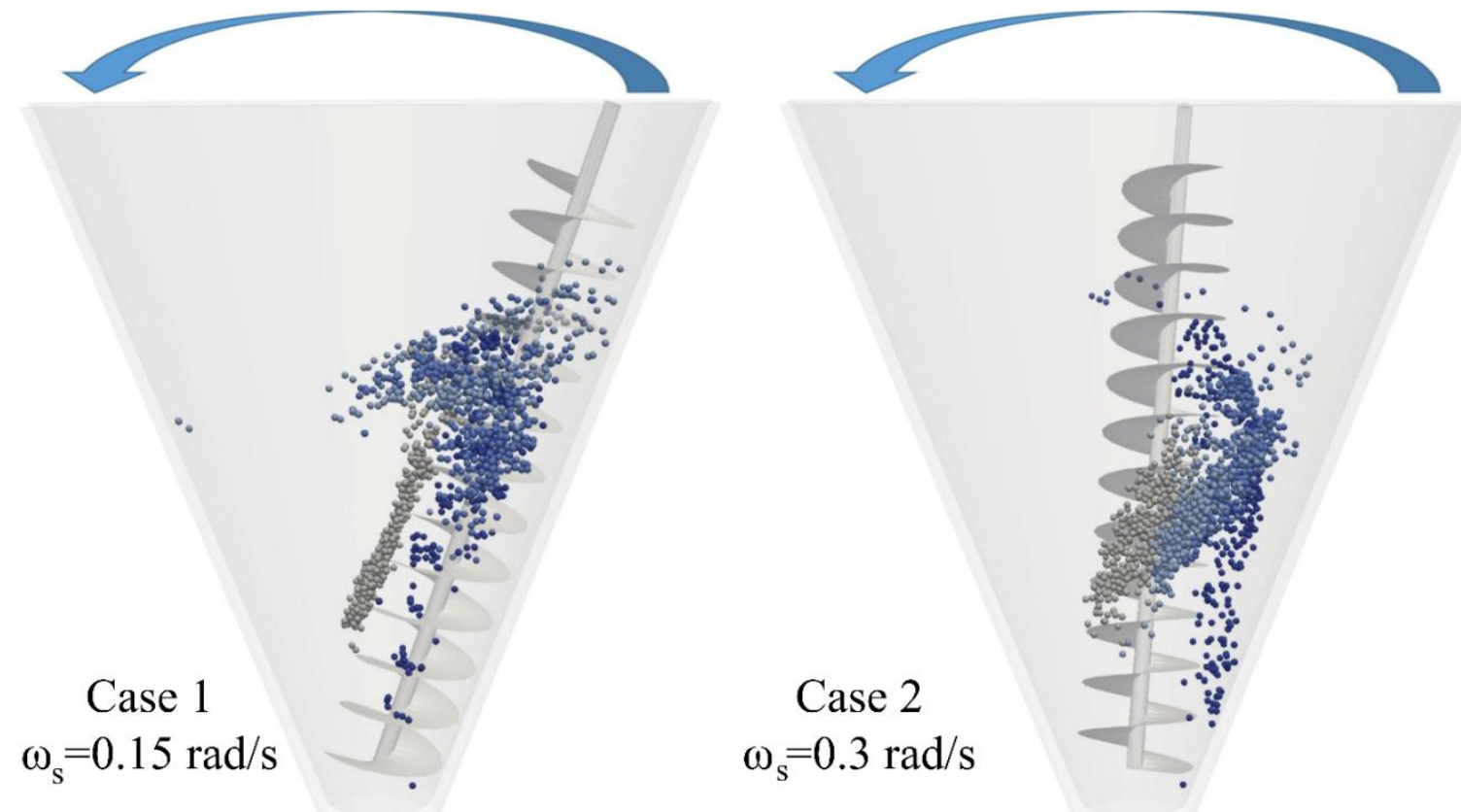

Fig. 12. Distribution of particles inside three middle spheres (shown in Fig. 8) on the blender body axis for cases 1 and 2 at $t=2.6 \mathrm{~s}$. Primary rotation velocity $=7.5 \mathrm{rad} / \mathrm{s}$ and impeller diameter $=10.8 \mathrm{~cm}$. 


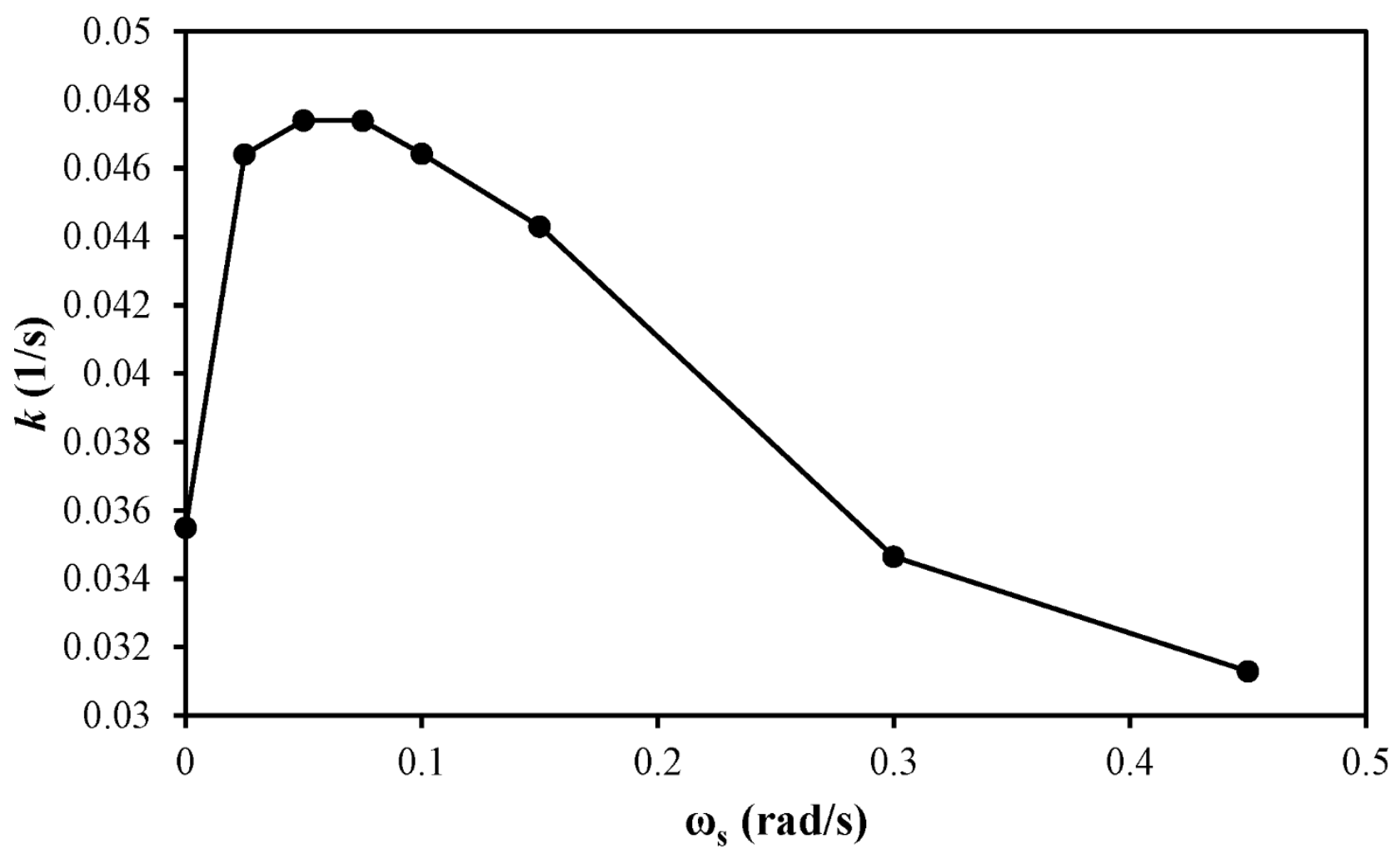

Fig. 13. Effect of sweeping velocity on mixing rate $(k)$. Primary rotation velocity $=7.5 \mathrm{rad} / \mathrm{s}$ and impeller diameter $=10.8 \mathrm{~cm}$. 


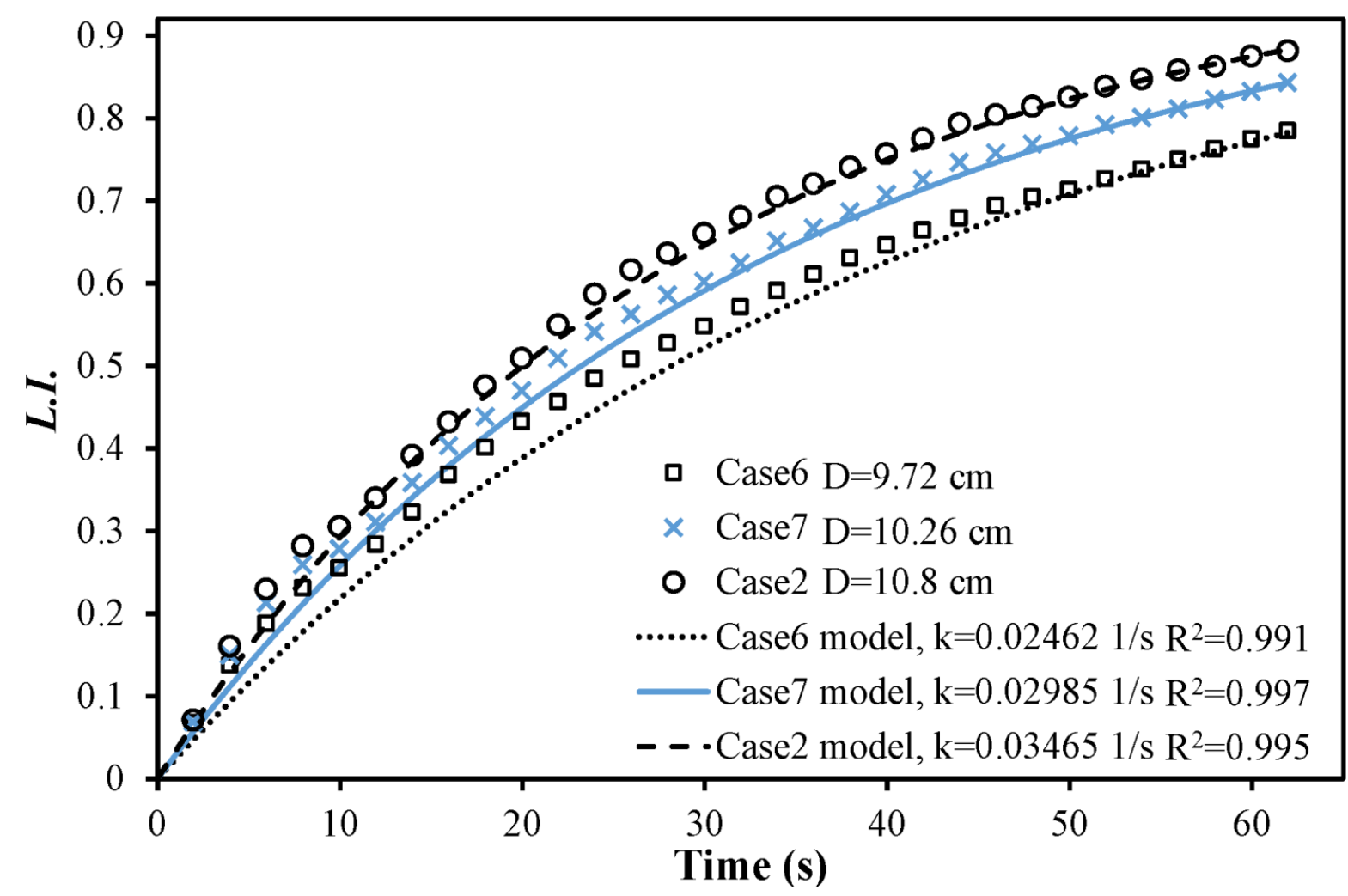

Fig. 14. Mixing index in Nauta blender as a function of time at various impeller diameters. Sweeping velocity $=0.3 \mathrm{rad} / \mathrm{s}$ and primary rotation velocity $=7.5 \mathrm{rad} / \mathrm{s}$. 
Table 1. Dimensions of body and screw impeller of the Nauta blender used in simulations.

\begin{tabular}{ll}
\hline Parameter & Value $(\mathbf{m})$ \\
\hline $\mathrm{R}_{1}$ & 0.56 \\
$\mathrm{R}_{2}$ & 0.11 \\
$\mathrm{D}$ & $0.108,0.1026,0.0972$ \\
$\mathrm{~L}$ & 0.62 \\
Initial filled height & 0.34 \\
Screw pitch & $0.063,0.0665,0.07$ \\
Impeller thickness & 0.001 \\
Clearance distance & 0.003 \\
\hline
\end{tabular}


Table 2. Simulation parameters used for validation (from [38]).

\begin{tabular}{ll}
\hline Parameter & Value \\
\hline Particle diameter & $9.4 \mathrm{~mm}$ \\
Particle density & $800 \mathrm{~kg} / \mathrm{m}^{3}$ \\
Number of particles & 1864 \\
Stiffness coefficient & $125 \mathrm{~N} / \mathrm{m}$ \\
Damping coefficient & $0.079 \mathrm{~kg} / \mathrm{s}$ \\
Friction coefficient & 0.5 \\
Rolling friction coefficient & 0.0001 \\
\hline
\end{tabular}


Table 3. Simulation parameters and operating condition of the simulation.

\begin{tabular}{|c|c|c|c|}
\hline Parameter & Symbol & Type & Value \\
\hline Particle density $\left(\mathrm{kg} / \mathrm{m}^{3}\right)$ & $\rho$ & & 2500 \\
\hline Particle diameter (mm) & $d$ & & 6 \\
\hline Number of particles & - & & 90000 \\
\hline \multirow[t]{2}{*}{ Young's modulus $(\mathrm{Pa})$} & $E$ & Particle-Particle & $10^{8}$ \\
\hline & & Particle-Wall & $10^{8}$ \\
\hline \multirow[t]{2}{*}{ Poisson's ratio } & $v$ & Particle-Particle & 0.25 \\
\hline & & Particle-Wall & 0.23 \\
\hline \multirow[t]{2}{*}{ Coefficient of restitution } & $e$ & Particle-Particle & 0.5 \\
\hline & & Particle-Wall & 0.7 \\
\hline \multirow[t]{2}{*}{ Rolling friction coefficient } & $\mu_{\mathrm{r}}$ & Particle-Particle & 0.0001 \\
\hline & & Particle-Wall & 0.01 \\
\hline \multirow[t]{2}{*}{ Friction coefficient } & $\mu$ & Particle-Particle & 0.5 \\
\hline & & Particle-Wall & 0.2 \\
\hline Time step (s) & $\Delta t$ & - & $1 \times 10^{-6}$ \\
\hline Simulation time (s) & - & - & 62 \\
\hline
\end{tabular}


Table 4. Operating conditions of simulated cases.

\begin{tabular}{|c|c|c|c|c|}
\hline & & $\begin{array}{l}\text { Sweeping velocity } \\
(\mathrm{rad} / \mathrm{s})\end{array}$ & $\begin{array}{l}\text { Primary rotation velocity } \\
(\mathrm{rad} / \mathrm{s})\end{array}$ & $\begin{array}{c}\text { Impeller diameter } \\
(\mathrm{cm})\end{array}$ \\
\hline & Case 1 & 0.15 & 7.5 & 10.8 \\
\hline \multirow[t]{3}{*}{1} & Case 2 & 0.3 & 7.5 & 10.8 \\
\hline & Case 3 & 0.45 & 7.5 & 10.8 \\
\hline & Case 4 & 0.3 & 5 & 10.8 \\
\hline \multirow[t]{3}{*}{2} & Case 2 & 0.3 & 7.5 & 10.8 \\
\hline & Case 5 & 0.3 & 10 & 10.8 \\
\hline & Case 6 & 0.3 & 7.5 & 9.72 \\
\hline \multirow[t]{2}{*}{3} & Case 7 & 0.3 & 7.5 & 10.26 \\
\hline & Case 2 & 0.3 & 7.5 & 10.8 \\
\hline
\end{tabular}



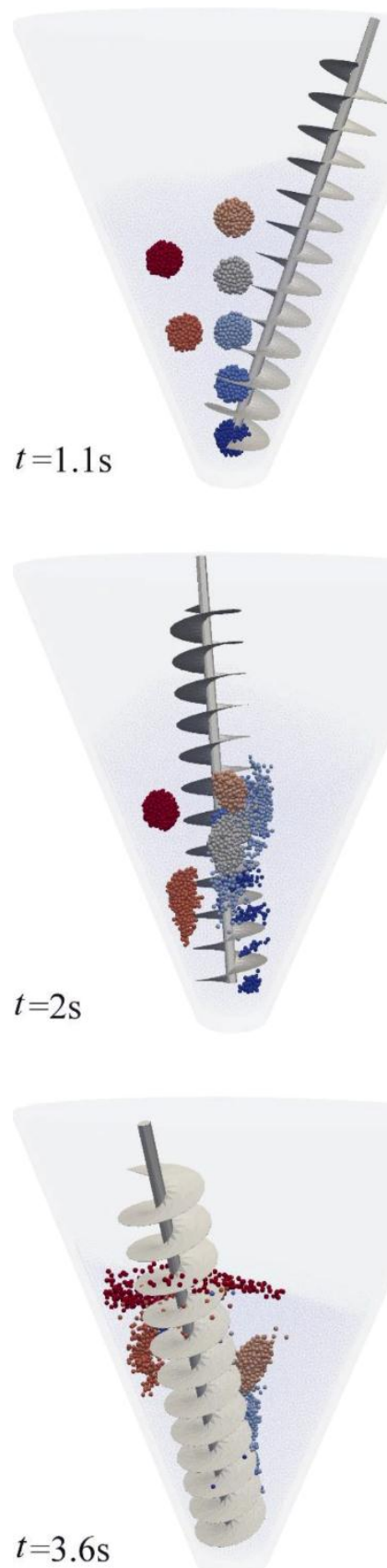
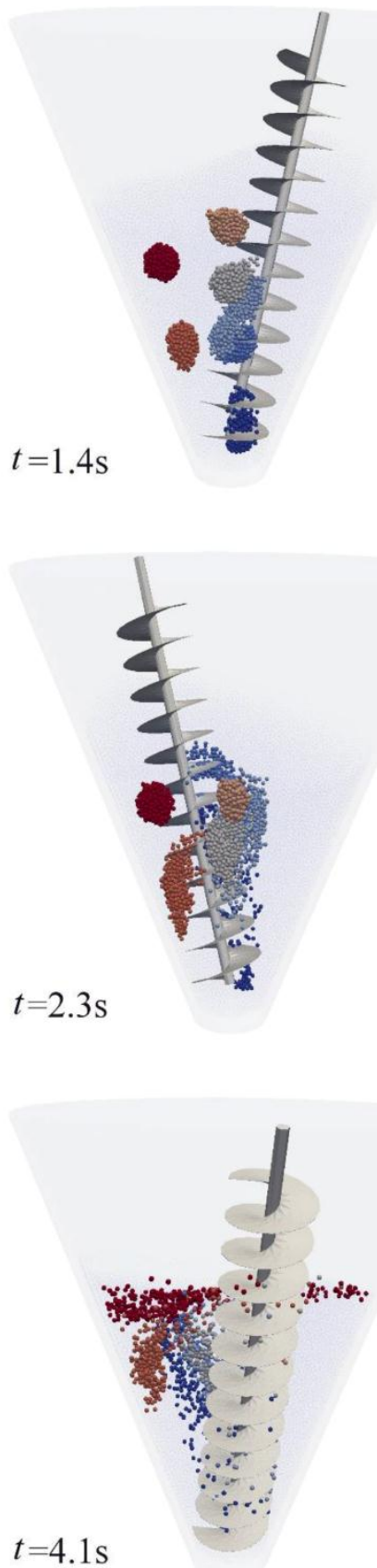
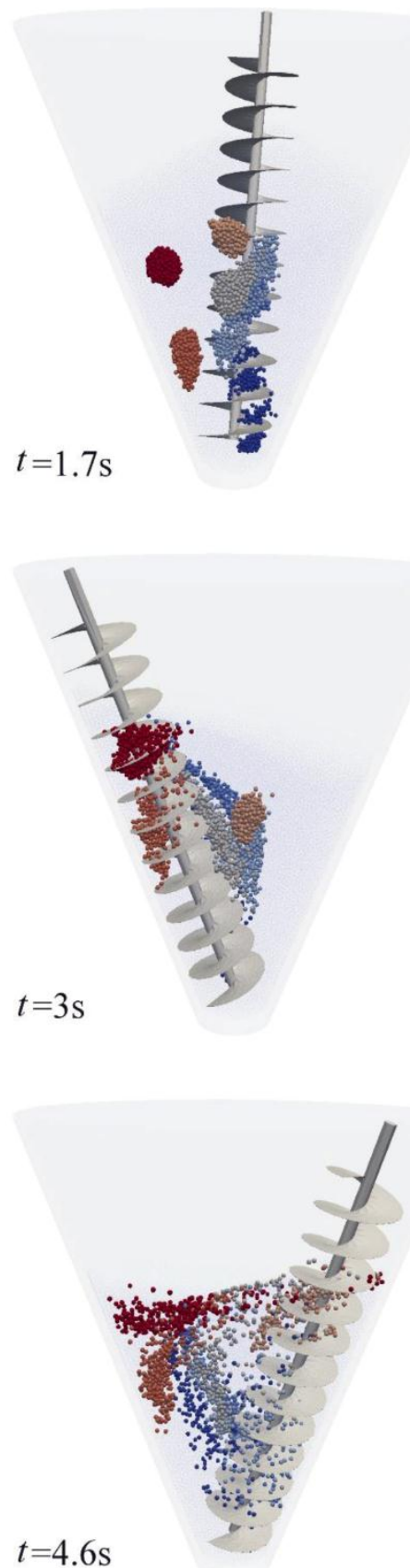